Article

\title{
The bRPS6-Family Protein RFC3 Prevents Interference by the Splicing Factor CFM3b during Plastid rRNA Biogenesis in Arabidopsis thaliana
}

\author{
Yumi Nagashima ${ }^{1}$, Katsutomo Ohshiro ${ }^{1}$, Akiyasu Iwase ${ }^{1}$, Miyuki T. Nakata ${ }^{2,3}$, \\ Shugo Maekawa ${ }^{1,2}$ and Gorou Horiguchi ${ }^{1,2, *(1)}$ \\ 1 Department of Life Science, College of Science, Rikkyo University, Toshima, Tokyo 171-8501, Japan; \\ 18ld007d@rikkyo.ac.jp (Y.N.); katsutomo0204@gmail.com (K.O.); iws.office.akys@gmail.com (A.I.); \\ maeshu@rikkyo.ac.jp (S.M.) \\ 2 Research Center for Life Science, College of Science, Rikkyo University, Toshima, Tokyo 171-8501, Japan; \\ miyuki-t-nakata@bs.naist.jp \\ 3 Graduate School of Science and Technology, Nara Institute of Science and Technology, Ikoma, \\ Nara 630-0192, Japan \\ * Correspondence: ghori@rikkyo.ac.jp
}

Received: 3 February 2020; Accepted: 3 March 2020; Published: 4 March 2020

\begin{abstract}
Plastid ribosome biogenesis is important for plant growth and development. REGULATOR OF FATTY ACID COMPOSITION3 (RFC3) is a member of the bacterial ribosomal protein S6 family and is important for lateral root development. $r f c 3-2$ dramatically reduces the plastid rRNA level and produces lateral roots that lack stem cells. In this study, we isolated a suppressor of rfc three2 (sprt2) mutant that enabled recovery of most $r f c 3$ mutant phenotypes, including abnormal primary and lateral root development and reduced plastid rRNA level. Northern blotting showed that immature and mature plastid rRNA levels were reduced, with the exception of an early $23 \mathrm{~S}$ rRNA intermediate, in $r f c 3-2$ mutants. These changes were recovered in $r f c 3-2$ sprt2-1 mutants, but a second defect in the processing of $16 \mathrm{~S}$ rRNA appeared in this line. The results suggest that $r f c 3$ mutants may be defective in at least two steps of plastid rRNA processing, one of which is specifically affected by the sprt2-1 mutation. sprt2-1 mutants had a mutation in CRM FAMILY MEMBER $3 b$ (CFM3b), which encodes a plastid-localized splicing factor. A bimolecular fluorescence complementation (BiFC) assay suggested that RFC3 and SPRT2/CFM3b interact with each other in plastids. These results suggest that RFC3 suppresses the nonspecific action of SPRT2/CFM3b and improves the accuracy of plastid rRNA processing.
\end{abstract}

Keywords: Arabidopsis; CFM3b; lateral root; plastid; RFC3; ribosome; rRNA biogenesis; sprt2

\section{Introduction}

During plant evolution, endosymbiotic ancestral cyanobacteria and $\alpha$-proteobacteria were engulfed by host eukaryotic cells and evolved into plastids and mitochondria, respectively [1,2]. Thus, plants have three different types of ribosomes classified as prokaryotic (mitochondrial and plastidial ribosomes) and eukaryotic (cytosolic ribosomes). The 705 plastid ribosome is composed of a $50 \mathrm{~S}$ subunit and a $30 \mathrm{~S}$ subunit. The $50 \mathrm{~S}$ subunit includes approximately 30 ribosomal proteins (RPs) as well as 23S, 5S, and 4.5S rRNAs, while the $30 \mathrm{~S}$ subunit includes approximately $20 \mathrm{RPs}$ and $16 \mathrm{~S}$ rRNA [3-6]. Among the components of the plastid translation system, RPs are encoded in the plastid and nuclear genomes [7], while all tRNAs and rRNAs are encoded by the plastid genome [8]. The rRNAs are transcribed from single operon containing $r r n 16, \operatorname{trnI}, \operatorname{trn} A, r r n 23, r r n 4.5, r r n 5$, and $\operatorname{trnR}$, in this order; these rRNAs undergo processing by endonucleolytic cleavage, exonucleolytic trimming, 
nucleotide modifications, and ternary structure folding [7,9-13]. Primary rrn transcripts are cleaved into three fragments, each containing pre-16S, pre-23S-4.5S, and pre-5S rRNAs. The pre-23S-4.5S rRNA is cleaved into pre-23S and pre-4.5S rRNAs. These monocistronic fragments are trimmed to yield mature rRNAs. Concurrently, RPs bind immature rRNAs to assist their folding and produce mature $30 S$ and $50 S$ subunits. These processes are assisted by multiple ribosome biogenesis factors [7]. The mature 23S rRNA is further cleaved into three fragments at sites known as hidden breaks [14]. Thus far, many plastidial ribosome biogenesis factors have been identified, but details of ribosome biogenesis in plastids remains unclear.

RNA splicing also plays an important role in successful gene expression in plastids. The plastid genome contains groups I and II introns; group II introns are divided into subclasses IIA and IIB [15]. These introns do not exhibit autocatalytic activity and require proteinaceous factors [16]. Biochemical and molecular genetic analyses in Arabidopsis thaliana (hereafter, Arabidopsis), maize, and rice have identified many factors involved in RNA splicing in plastids [17]. Among them, chloroplast RNA splicing and ribosome maturation (CRM) domain proteins have been extensively characterized [18]. The CRM domain has a conserved GxxG motif and RNA binding activity has been demonstrated in some CRM domain proteins [18]. The only CRM domain protein in Escherichia coli, YhbY, has a single CRM domain; this protein binds to pre-50S ribosomes and promotes their maturation [18]. A recent study discovered that YhbY also plays a role in 30S subunit biogenesis [19]. CRM domain proteins in plants diversified during evolution and are classified into four subfamilies (CHLOROPLAST RNA SPLICING1 [CRS1] and CRS2-ASSOCATED FACTOR [CAF], subfamilies 3 and 4), according to the number of CRM domains and the presence or absence of additional motifs [18]. CAF1 and CAF2 contain two CRM domains and are involved in the splicing of group IIB introns in plastids [20]. They recognize different subsets of group IIB introns and form heterodimers with CRS2, an RNA splicing factor related to peptidyl-tRNA hydrolase $[20,21]$. The CRS1 subfamily members have three or four CRM domains and include CFM2 and CFM3 [18]. Thus far, all known CRS1 subfamily members localize to plastids and promote RNA splicing [16,18,22-24]. CRS1 specifically binds the group IIA intron of $a t p F$ and promotes its folding into the tertiary structure necessary for its catalytic activity [16]. On the other hand, CFM2 is involved in the splicing of $\operatorname{trnL}$ (a group I intron), as well as $n d h A$ and $y f c 3$ intron1 (group IIB introns) [24]. In maize, CFM3 also promotes splicing of a different subset of group IIB introns $(n d h B$, petB, petD, rpl16, rps16, and trnG), relative to those recognized by CFM2 [23]. In Arabidopsis, CFM3 has two paralogs, CFM3a and CFM3b, both of which are localized in plastids; these paralogs presumably play redundant roles in group IIB intron splicing, in which CFM3a has a major role [23]. Two other CRM domain proteins, CFM9 and mitochondria CAF-like splicing factor 1 (mCSF1), localize to mitochondria and are involved in splicing of mitochondrial transcripts $[25,26]$.

Although most CRM domain proteins in plants play crucial roles in the splicing of organellar groups I and II introns, a few have different roles. For example, CFM4 localizes to plastids and is suspected to be involved in $16 \mathrm{~S}$ and $4.5 \mathrm{~S}$ processing via its RNA chaperone activity [27]. Interestingly, CFM3 in maize and CFM3a (but not CFM3b) in Arabidopsis are also targeted to mitochondria and play roles in mitochondrial ribosome small subunit maturation [23].

Plastid development and plastid ribosome biogenesis are coordinated with the roles of plastids in different cell types, tissues, and organs, as well as with changes in environmental conditions. However, apart from chloroplast biogenesis in response to light [28-30], little is known regarding the mechanisms underlying this coordination in non-photosynthetic organs [31,32]. We previously identified REGULATOR OF FATTY ACID COMPOSITION3 (RFC3) as a member of the bacterial ribosomal protein S6 (bRPS6) family and found that it is important for lateral root (LR) development [33-35]. The plastid ribosome contains a bona fide RPS6 encoded by the nuclear PLASTID RIBOSOMAL PROTEIN S6 (PRPS6) gene, which originates from the cyanobacterial ancestor [34,35]. Although plastid RPs retain considerable homology with their bacterial RP counterparts [7], RCF3 is distantly related to PRPS6 and is rather placed in the same clade as $\beta / \gamma$ proteobacteria [35]. 
Loss-of-function of RFC3 results in striking reductions in the 23S and 16S rRNA levels in roots [35]. Therefore, RFC3 may be involved in the biogenesis or stability of plastid rRNAs.

$r f c 3$ mutants show an interesting developmental defect; they fail to complete patterning of the root apical meristem (RAM) in LRs [33,34]. In Arabidopsis, LR formation is divided into stages I to VII and initiate from pericycle cells associated with protoxylem poles [36]. During the course of LR development, specific modules of AUXIN RESPONSE FACTOR (ARF) transcription factors and AUXIN/INDOLE ACETIC ACID (AUX/IAA) repressor proteins, as well as other downstream transcription factors, specify LR primordium (LRP), founder cells and promote LR formation [37-39]. In parallel, three PLETHORA transcription family members-PLT3, PLT5, and PLT7-contribute to the establishment of LRPs [40]. During LR development, quiescent center (QC) is established by the action of a transcription factor complex comprising PLT, SCARECROW (SCR), and several members of TEOSINTE BRANCHED1/CYCLOIDEA/PCF (TCP) through activation of WUSCHEL-RELATED HOMEOBOX5 (WOX5) expression [41,42]. While these studies have advanced our understanding of the molecular and cellular processes of LR development, another process may be required for appropriate LR development as described below.

The $r f c 3$ mutant produces nodule-like LRs that lack a QC and a functional RAM [35]. Furthermore, the expression levels of PLT3 and PLT7 are higher in roots of $r f c 3$ mutants than in the wild type (WT) [35]. Because WT plants treated with translation inhibitors for bacteria-type ribosomes develop $r f c 3$-like abnormal LRs, plastid ribosomes likely play important roles in LR development [35]. To better understand the relationships among RFC3, plastid ribosome, and development of primary root (PR) and LR, we carried out suppressor screening using $r f c 3-2$ mutants. We recovered suppressor of $r f c$ three (sprt) mutants in which both abnormal PR and LR development and the reduced plastid rRNA level were rescued. We then identified the causal gene of the sprt2 mutation as CFM $3 b$ and revealed interactions between RFC 3 and CFM $3 b$ in plastids. In the context of these findings, we discuss the potential, yet unexpected, link between rRNA processing and splicing factors in plastids.

\section{Results}

\subsection{Identification of Sprt Mutants}

$r f c 3-2$ mutants were isolated from the Landsberg erecta (Ler) background and produced short PRs with abnormal nodule-like LRs (Figure 1) [33,34]. Three suppressors (EMS33, EMS68, EMS81) of $r f c 3$ with elongated PRs and normal LRs were identified by visual inspection from EMS-mutagenized M2 populations (Figure 1a,c). EMS33 showed near full recovery of PR length compared to WT roots, while EMS81 had the shortest PRs among the three suppressors. EMS68 had an intermediate PR length (Figure 1c). The three suppressors produced LRs with a well-organized RAM, compared to the disorganized RAM in $r f c 3-2$ mutants (Figure 1b). The PR and LR phenotypes in F1 progenies among the three suppressors and $r f c 3-2$ mutants indicated that the second-site mutations in EMS33, EMS68, and EMS81 behaved as semi-dominant, recessive, and dominant alleles, respectively, when focused on the LR phenotype (Figure S1). Due to the semi-dominant and dominant behaviors of mutations in EMS 33 and EMS 81, allelism tests among the three suppressors were impractical (Figure S1). We thus tentatively assigned mutated loci in EMS33, EMS68, and EMS81 as sprt1-1, sprt2-1, and sprt3-1, respectively. We use the term "sprts" to refer to these mutants collectively. 


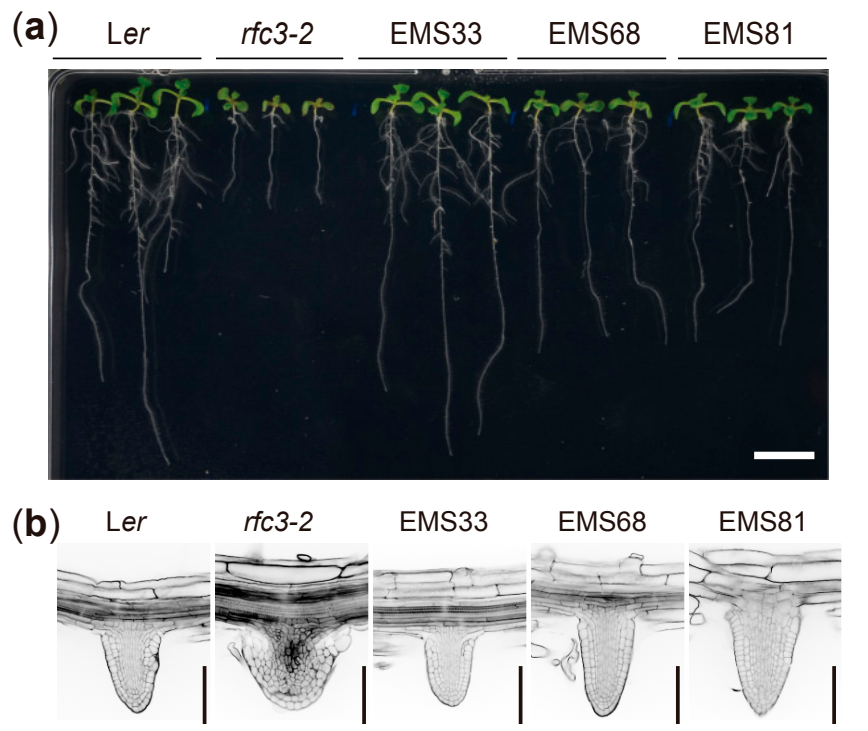

(c)

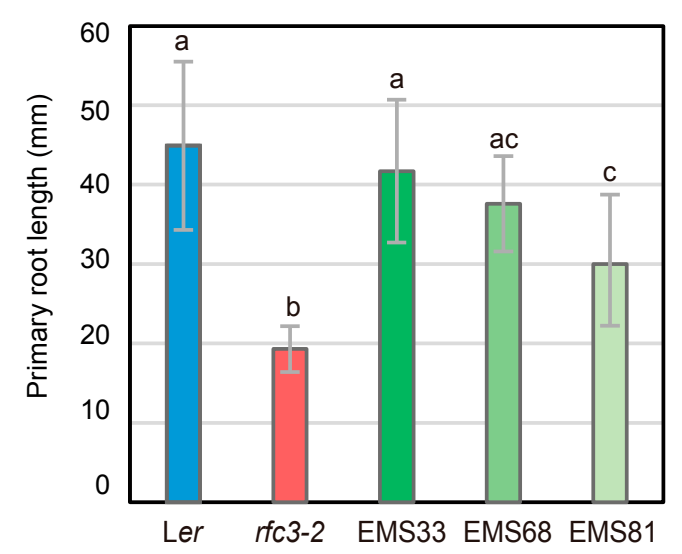

Figure 1. Isolation of $r f c 3$ suppressor mutants. (a) Plants grown on $1 / 2 \mathrm{MS}$ medium containing $3 \%$ sucrose for $11 \mathrm{~d}$. Bar $=1 \mathrm{~cm}$. (b) Lateral root (LR) phenotypes observed by modified pseudo-Schiff-propidium iodide (mPS-PI) staining. Bars $=100 \mu \mathrm{m}$. (c) Primary root $(\mathrm{PR})$ length. Data are means \pm SDs $(\mathrm{n} \geq 11)$. Statistical analysis was carried out by one-way ANOVA with Tukey HSD test $(p<0.05)$. Data without significant differences are labeled with the same letters. EMS33, EMS68, and EMS81 correspond to $r f c 3-2$ sprt1-1, rfc3-2 sprt2-1, and $r f c 3-2$ sprt3-1, respectively.

\subsection{Most rfc3 Mutant Phenotypes were Recovered by the sprt2-1 Mutation}

To characterize the extent to which sprts mutations suppressed $r f c 3$ mutant phenotypes, we examined several developmental, cellular, and gene expression phenotypes. $r f c 3-2$ mutants grew slowly and formed pale green leaves compared to WT plants [35]. A time-course analysis of leaf growth showed that in the early stages, $r f c 3-2, r f c 3-2$ sprt2-1, and $r f c 3-2$ sprt3-1 mutants formed smaller first leaves than WT plants, whereas the $r f c 3-2$ sprt1-1 mutants recovered this defect (Figure 2a,b). At the mature stage, however, neither $r f c 3-2$ nor $r f c 3-2$ sprts mutants produced smaller first leaves than WT leaves (Figure 2a,b). In WT but not $r f c 3-2$ roots, chlorophyll accumulated in plastids after prolonged exposure to light (Figure 2c). On the other hand, all $r f c 3-2$ sprts mutants re-accumulated chlorophyll in roots as determined by chlorophyll autofluorescence, albeit to a lesser extent than WT roots (Figure 2c).

Next, we selected $r f c 3-2$ sprt2-1 mutants to further characterize gene expression phenotypes in roots by RT-qPCR, since we succeeded identification of the sprt2-1 mutation point as described in a later part of this study (Figure 7). The identification of sprt2-1 mutation site also allowed isolation of sprt2-1 single mutants and they were included in some of following experiments. Further characterization of rfc3-2 sprt1-1, rfc3-2 sprt3-1, and corresponding single mutants will be reported elsewhere. The RNA expression levels of stem-cell regulatory genes, such as WOX5, PLT3, PLT7, and CLAVATA1 (CLV1) [43], were increased in roots of $r f c 3-2$ mutants, compared to WT plants (Figure 3a) [35]. In $r f c 3-2$ sprt2-1 mutants, these genes were expressed at levels nearly identical to those in WT plants (Figure 3a). We also investigated the expression levels of several plastid-encoded genes in roots. Expression levels of $p s b A$ and $p s b B$ significantly decreased, while expression levels of $r p o B$, prps $18, c l p P$, and $n d h A$ significantly increased in $r f c 3-2$ mutants (Figure $3 b$ ). In $r f c 3-2$ sprt2-1 mutants, $p s b A$ and $p s b B$ were expressed at levels similar to those in WT plants (Figure 3b). In addition, rpoB, prps18, $\operatorname{llpP}$, and $n d h A$ expression levels were only slightly higher in $r f c 3-2$ sprt2-1 mutants than in WT plants (Figure $3 b$ ). The expression levels of $a c c D$ and $r b c L$ did not show clear differences among the genotypes examined (Figure $3 \mathrm{~b}$ ). The expression levels of the above-mentioned nuclear and plastid RNAs in sprt2-1 single mutants were similar to those in WT plants (Figure 3a,b). 
(a)

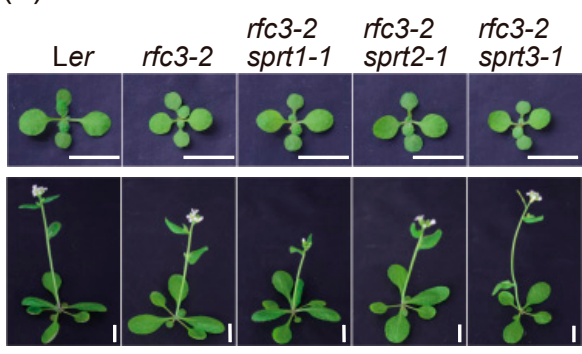

(c) (b)

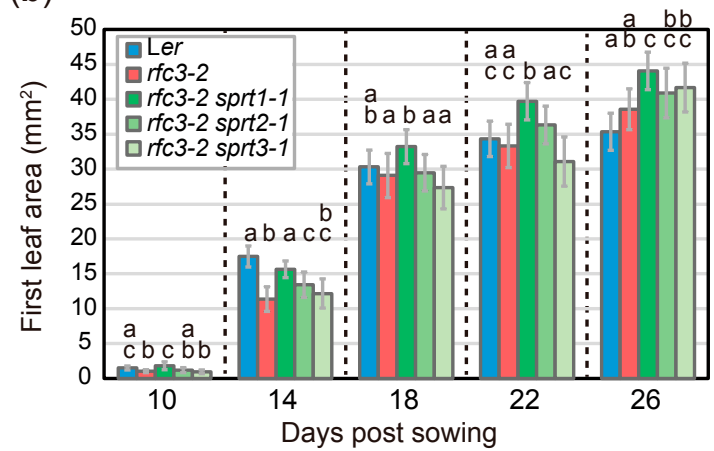

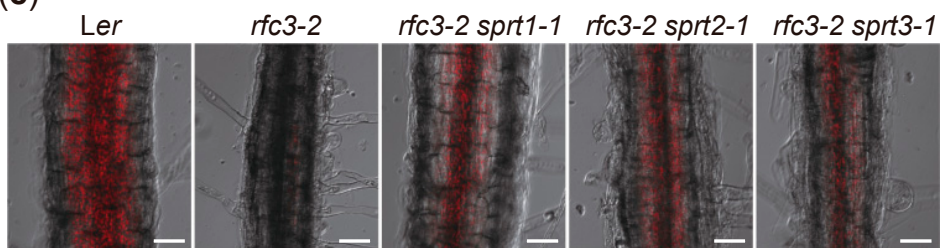

Figure 2. Shoot phenotypes and differentiation potentials of chloroplasts in $r f c 3$ and $r f c 3$ sprts. (a) Shoot phenotypes. Plants grown for $14 \mathrm{~d}$ (upper row) or $26 \mathrm{~d}$ (lower row) are shown. Bars $=1 \mathrm{~cm}$. (b) Time-course analysis of first leaf area. Data are means \pm SDs $(n \geq 12)$. For each group of samples harvested at different days, statistical analysis was carried out separately by one-way ANOVA with Tukey HSD test $(p<0.05)$. Data without significant differences are labeled with the same letters. (c) Differentiation of chloroplasts in the mature region of PRs. Chlorophyll autofluorescence (red) was merged with bright-field images. Bars $=50 \mu \mathrm{m}$.

(a)

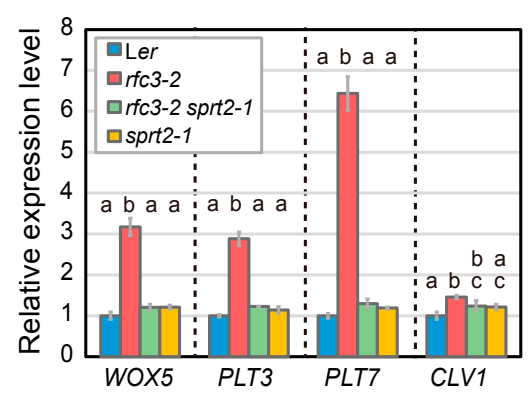

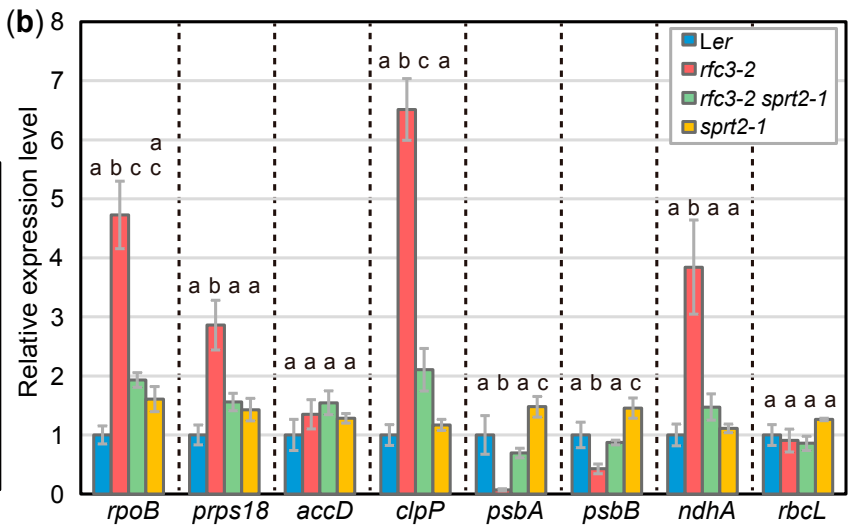

Figure 3. RNA expression of nuclear- and plastid-encoded genes in roots as determined by RT-qPCR. (a) Relative expression levels of nuclear-encoded genes normalized by ACT2 expression level. (b) Relative expression levels of plastid-encoded genes normalized by $18 \mathrm{~S}$ rRNA level. Data are means \pm SDs. $(n=3)$. Statistical analysis was carried out by one-way ANOVA with Tukey HSD test for each mRNA species $(p<0.05)$. Data without significant differences are labeled with the same letters.

Next, we examined the spatial expression patterns of LR regulatory genes during LR development. Expression of pWOX5::GREEN FLUORESCENT PROTEIN (GFP) was QC-specific in WT plants, whereas it was expressed throughout the LRPs in $r f c 3-2$ mutants (Figure 4a) [35]. In $r f c 3-2$ sprt2-1 mutants, the expression of pWOX5::GFP was expanded, but partially localized to QCs of LRPs (Figure 4a). Furthermore, in nearly all mature LRs of $r f c 3-2$ sprt2-1 mutant, pWOX5::GFP was expressed specifically in QC cells (Figure S2). pPLT3::CYAN FLUORESCENT PROTEIN (CFP) was expressed in early LRPS and mainly in the stem-cell niche in mature LRs (Figure 4b) [44]. In $r f c 3-2$ mutants, the pPLT3::CFP expression pattern in the early LRPs was relatively normal, but may be upregulated during stages IV-V 
and disappeared in completely differentiated abnormal LRs (Figure $4 b$ ). This result alone is difficult to explain the enhanced expression of PLT3 in $r f c 3-2$ mutants (Figure 3a). To solve this inconsistency, we focused on LR and LRP density. pPLT3::CFP is active throughout LRP development and in mature LRs in the WT plants and $r f c 3-2$ sprt2-1 mutants (Figure $4 \mathrm{~b}$ ). On the other hand, mature LRs in $r f c 3-2$ lost the pPLT3::CFP expression (Figure $4 \mathrm{~b}$ ). Therefore, we counted the numbers of CFP-positive LRs and LRPs, respectively, and their density were determined by dividing with the PR length of individual plants. Concerning LRP, $r f c 3-2$ had about 2-fold higher density than WT plants and $r f c 3-2$ sprt2-1 mutants (Figure $4 \mathrm{~d}$ ). When densities of LRP plus LR were compared, $r f c 3-2$ mutants had only about 1.5-fold higher density than WT plants, reflecting disappearance of pPLT3::CFP expression in fully differentiated abnormal LRs in $r f c 3-2$ mutants. (Figure $4 \mathrm{c}, \mathrm{d}$ ). Therefore, while the expression of WOX5 increased in $r f c 3-2$ mutants due to a combined effect of ectopic expression in LRPs and an increased density of LRPs, the increased expression of PLT3 in $r f c 3-2$ mutants was mainly due to the increased LRP density in $r f c 3-2$ mutants.

(a)

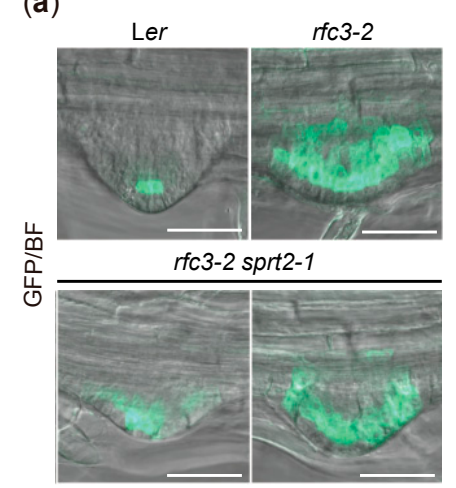

(b)

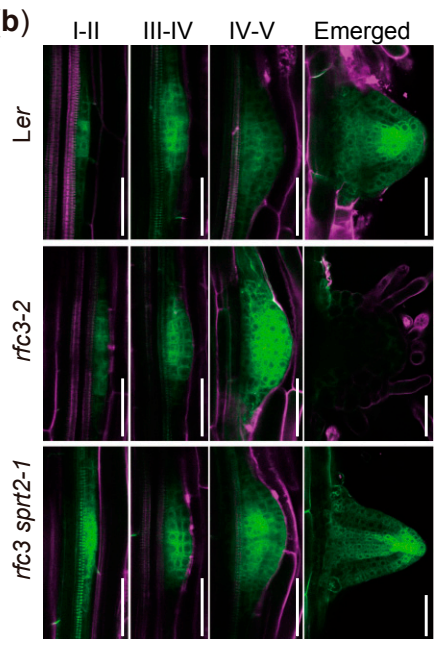

(c)

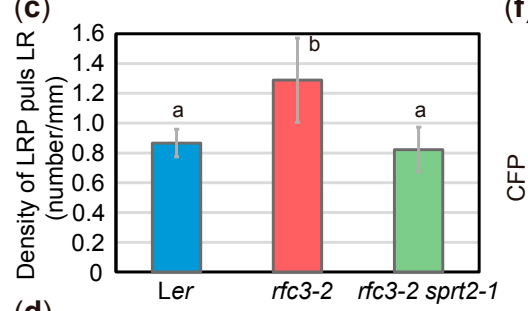

(d) 1.4

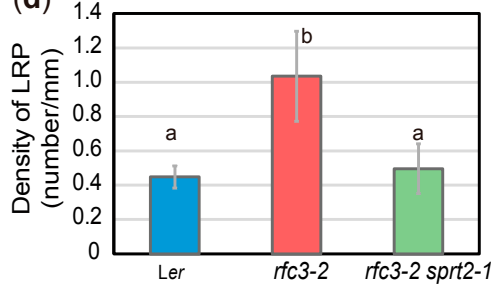

(e)

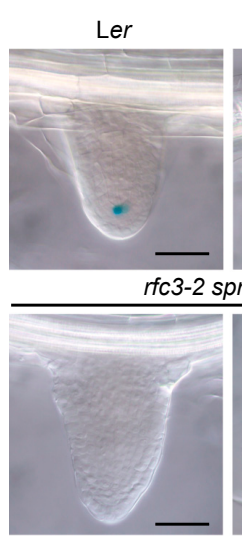

rfc3-2
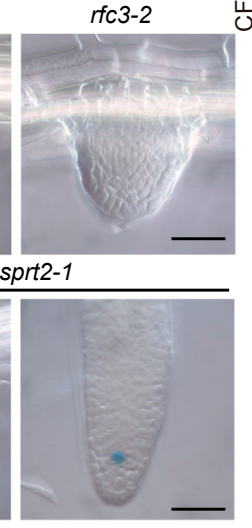

(f)

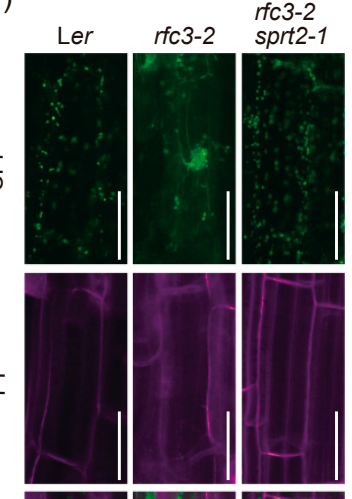

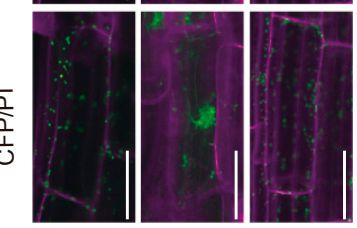

Figure 4. Reporter analyses of $r f c 3-2$ and $r f c 3-2$ sprt2-1 mutants. (a) pWOX5::GFP patterns (green) merged with bright-field (BF) images in LR primordia (LRPs). Bars $=100 \mu \mathrm{m}$. (b) pPLT3::CFP patterns in LRPs at different stages. pPLT3::CYAN FLUORESCENT PROTEIN (CFP) fluorescence is shown in green; roots were stained with propidium iodide (PI, magenta). Bars $=50 \mu \mathrm{m}$. (c) Density of CFP-positive LRPs plus LRs in PR of pPLT3::CFP lines at 7 days post sowing (dps). (d) Density of CFP-positive LRPs in PR of pPLT3::CFP lines at $7 \mathrm{dps}$. In (c) and (d), statistical analysis was carried out by one-way ANOVA with Tukey HSD test ( $p<0.05, \mathrm{n}=10$, means \pm SDs). Data without significant differences are labeled with the same letters. (e) QC25 expression patterns in emerged LRs. Bars = $50 \mu \mathrm{m}$. Lower left and right panels show a young and an elongated LRs, respectively. (f) Intracellular distribution of plastids observed in p35S::RecATP-CFP lines. CFP fluorescence is shown in green; roots were stained with PI (magenta). Bars $=50 \mu \mathrm{m}$. 
We next examined the identities of QC in LRPs because $r f c 3-2$ mutants failed to establish LRs beyond stage VI, had no structurally discernable QC, and were devoid of QC25::GUS expression (Figure 4e) [35]. Expression of QC25::GUS was undetectable in young LRs of $r f c 3-2$ and $r f c 3-2$ sprt2-1 but expressed in sufficiently elongated $r f c 3-2$ sprt2-1 LRs (Figure 4e). Under our experimental conditions, QC184::GUS was expressed in QC, as well as the mature parts of WT roots (Figure S3). In fully differentiated $r f c 3-2$ mutant LRs, the strong GUS signal likely reflected expression of QC184::GUS in mature roots, rather than expression caused by ectopic QC identity (Figure S3). In elongating LRs of rfc3-2 sprt2-1 mutants, QC184::GUS expression was not observed (Figure S3). Therefore, QC identity and function were progressively but incompletely restored in rfc3-2 sprt2-1 mutants. rfc3-2 mutants also exhibited alterations in the intracellular distributions of plastids in roots. When root plastids were visualized using CFP fused to the RecA transit peptide, plastid distribution was partially restored from a clustered pattern to a scattered pattern in rfc3-2 sprt2-1 mutants (Figure 4f).

\section{3. rfc3-2 sprt2-1 Mutants Exhibit Restoration of Plastid rRNA Accumulation}

The recovery of most $r f c 3$ mutant phenotypes in $r f c 3-2$ sprt2-1 mutants suggested that the sprt2-1 mutation affected a process associated with the molecular function of RFC3. Thus, we next analyzed plastid rRNAs and their precursors in roots of $r f c 3-2$ sprt2-1 mutants. The levels of $16 \mathrm{~S}$ and $23 \mathrm{~S}$ rRNAs in $r f c 3-2$ mutant roots were reduced to approximately $10 \%$ and $30 \%$ of the levels in WT plants, respectively (Figure 5a) [35]. In contrast, cytosolic and mitochondrial rRNA levels were similar in all genotypes examined (Figure 5a). In rfc3-2 sprt2-1 mutant roots, the respective 16S and 23S rRNA levels recovered to approximately half and nearly identical to those in WT roots (Figure 5a). The 16S and 23S rRNA levels were normal in srpt2-1 single mutants (Figure 5a). This finding suggested that the sprt2-1 mutation increased the $16 \mathrm{~S}$ and $23 \mathrm{~S}$ rRNA levels specifically in the $r f c 3$ mutant background.

We next examined rRNA processing by Northern blotting. An overview of rRNA processing in plastids is shown in Figure 5b. When a probe covering the entire 16S rRNA was used, the amount of $16 \mathrm{~S}$ rRNA was found to be greatly reduced in $r f c 3-2$ mutants (Figure $5 c$ ). Similarly, a probe specific to the $3^{\prime}$ region of the 1.7-kb 16S rRNA precursor revealed significant reduction in the level of this precursor in $r f c 3-2$ mutants (Figure $5 c$ ). In contrast, the mature 16S rRNA level was partially recovered in $r f c 3-2$ sprt2-1 mutants, but overaccumulation of the 1.7-kb 16S rRNA precursor was observed (Figure 5c). The $3.0-\mathrm{kb}$ precursor of $23 \mathrm{~S}$ rRNA is cleaved into a $2.8-\mathrm{kb} 23 \mathrm{~S}$ rRNA precursor and pre-4.5S rRNA, and then the $2.8-\mathrm{kb} 23 \mathrm{~S}$ rRNA is cleaved into three fragments $(1.25,1.05$, and $0.5 \mathrm{~kb})$ (Figure $5 \mathrm{~b}$ ). When a probe covering the entire $23 \mathrm{~S}$ rRNA was used, these three fragments were less abundant in $r f c 3-2$ mutants, compared to WT plants (Figure 5c). Two 23S rRNA species were cut at one hidden break (1.75 and $2.3 \mathrm{~kb}$ ), while uncut $23 \mathrm{~S}$ rRNA was $2.8 \mathrm{~kb}$. (Figure $5 \mathrm{~b}$ ); $1.75-\mathrm{kb}$ and $2.3-\mathrm{kb} 23 \mathrm{~S}$ rRNA species were less abundant in $r f c 3-2$ mutants than in WT plants, but were recovered to WT levels in $r f c 3-2$ sprt2-1 mutants (Figure 5c). An exception was the longest RNA species detectable using the 23S rRNA probe, which is likely the $2.8-\mathrm{kb} 23 \mathrm{~S} \mathrm{rRNA}$ and/or $3.0-\mathrm{kb}$ precursors, as it was also detectable by a probe for the $5^{\prime}$ region of $23 S$ rRNA (Figure $5 b, c$ ). The levels of these precursors seem to be less affected in $r f c 3-2$ mutants when the levels of these and shorter $23 \mathrm{~S}$ rRNA species were compared to those in WT plants (Figure 5c). To distinguish 3.0-kb precursor from 2.8-kb $23 \mathrm{~S}$ rRNA, we carried out RT-qPCR using a primer pair that amplifies cDNA corresponding to a region from the $3^{\prime}$ end of $23 \mathrm{~S}$ rRNA to the spacer region of that is found in the 3.0-kb 23S-4.5S rRNA and longer $(7.3 \mathrm{~kb})$ precursors. As a result, we found that $r f c 3-2$ mutants had about 1.9-fold higher level these rRNA precursors when compared to WT plants (Figure $5 \mathrm{~d}$ ), suggesting that either one or both of the 3.0-kb 23S-4.5S rRNA precursors and the 7.3-kb precursors over accumulated in $r f c 3-2$ mutants. On the other hand, $r f c 3-2$ sprt2-1 mutants showed an intermediate level of these precursors (Figure $5 \mathrm{~d}$ ). Therefore, in $r f c 3-2$ sprt2-1 mutants, the abnormal rRNA processing of $r f c 3-2$ mutants was largely restored. In contrast, sprt2-1 mutants did not show strong defects in the processing pattern (Figure $5 \mathrm{c}, \mathrm{d}$ ). 
(a)

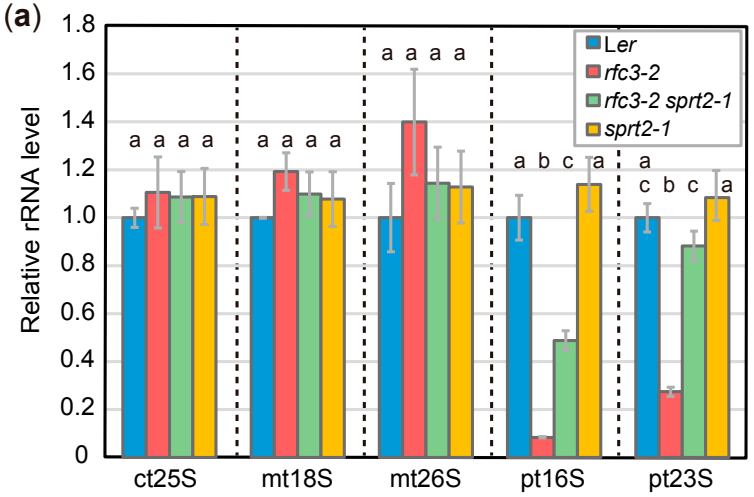

(b)

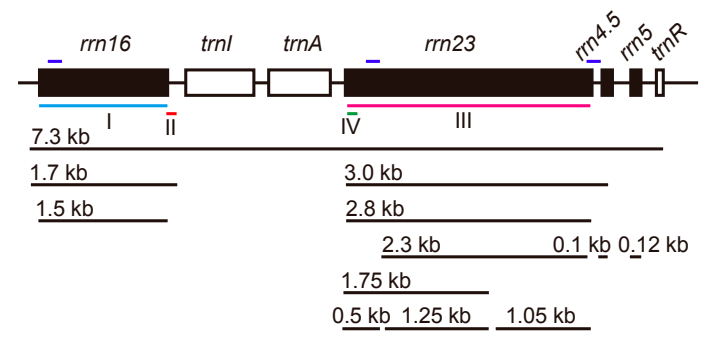

IV

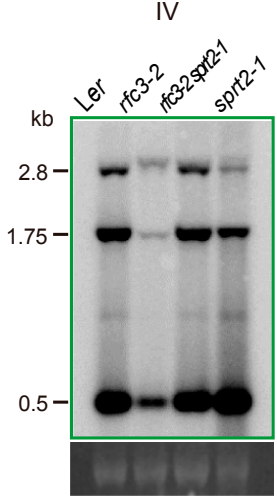

(d)

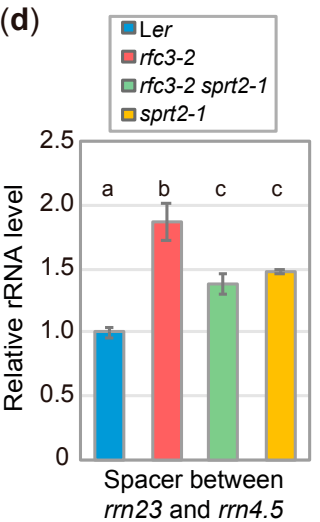

rrn23 and rrn4.5 (c)

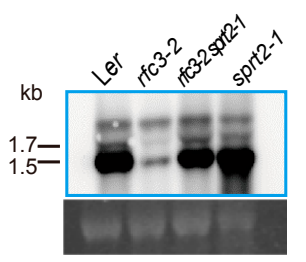

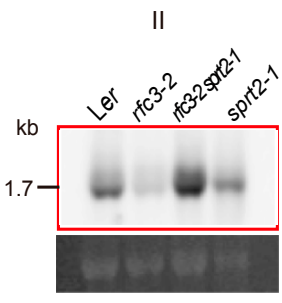

III

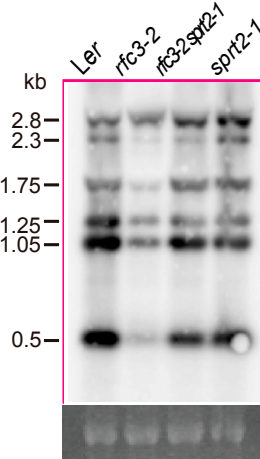

Figure 5. Analysis of rRNA accumulation and processing in $r f c 3-2$ and $r f c 3-2$ sprt2-1 mutants. (a) Cytosolic and organellar rRNA levels determined by RT-qPCR and normalized by $18 \mathrm{~S}$ rRNA level. $\mathrm{ct}, \mathrm{mt}$, and pt indicate cytosolic, mitochondrial, and plastid rRNAs, respectively. Data are means \pm SDs $(n=3)$. (b) Diagram of the plastid rRNA operon and the processing pattern. The position of probes for Northern analysis are indicated by colored bars below the diagram. The regions amplified by RT-qPCR are indicated by dark blue bars above the diagram. (c) Northern analysis of plastidial rRNA processing in roots. An ethidium bromide-stained image of $18 \mathrm{~S}$ rRNA is shown below each blot as a loading control. (d) Levels of spacer region between $r r n 23$ and $r r n 4.5$ determined by RT-qPCR. Data are means \pm SDs $(n=3)$. In (a) and (d), statistical analyses were carried out by one-way ANOVA with Tukey HSD test $(p<0.05)$. Data without significant differences are labeled with the same letters.

\subsection{Effect of the sprt2-1 Mutation on Plastid Ribosome Biogenesis}

Because the above results suggest that RFC3 is involved in plastid rRNA biosynthesis, we examined whether the sprt2-1 mutation could counteract the failure of plastid ribosome function caused by genetic or pharmacological means. For this, we used prps17-1 mutants, which are Ler background mutants that lack the plastid ribosomal protein PRPS17 [45]. Similar to $r f c 3-2$ mutants, prps17-1 mutants form shorter roots than those in WT plants. On the other hand, we did not find clear visible phenotypes of sprt2-1 single mutants in our experimental condition (Figure 6a). We generated sprt2-1 prps17-1 mutants, which formed PRs of similar length to those of prps17-1 mutants (Figure 6a,b). Treatment of WT plants with plastid translation inhibitors (e.g., spectinomycin) caused various phenotypes similar to those of $r f c 3-2$ mutants [35]. To determine whether the sprt2-1 mutation could counteract the effects of spectinomycin on PR growth, sprt2-1 mutants were grown on medium containing various concentrations of spectinomycin. In the presence of $>2 \mathrm{mg} / \mathrm{L}$ spectinomycin, both WT and sprt2-1 mutant plants formed shorter roots, similar to those of $r f c 3-2$ mutants (Figure 6c). However, sprt2-1 mutants showed greater sensitivity to $1 \mathrm{mg} / \mathrm{L}$ spectinomycin, compared to WT plants (Figure 6c). These findings indicated that the sprt2-1 mutation does not restore plastid ribosome deficiency, and that RFC3 and SPRT2 have a specific functional relationship. 
(a)

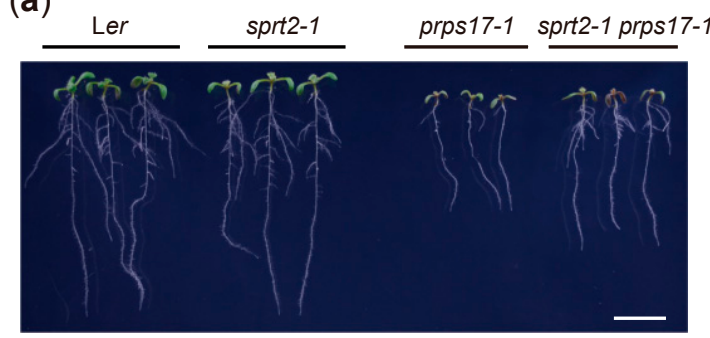

(c)

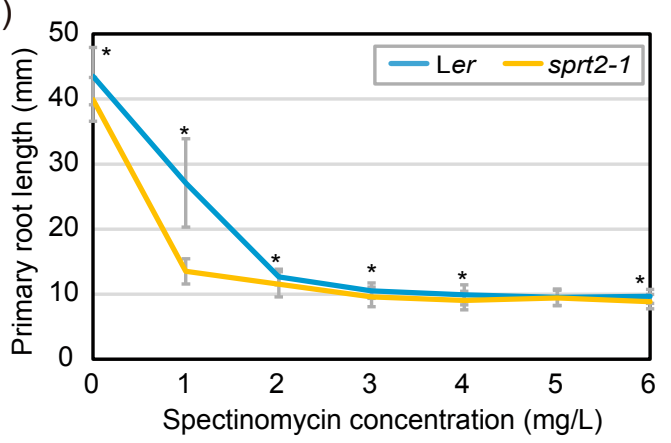

(b)

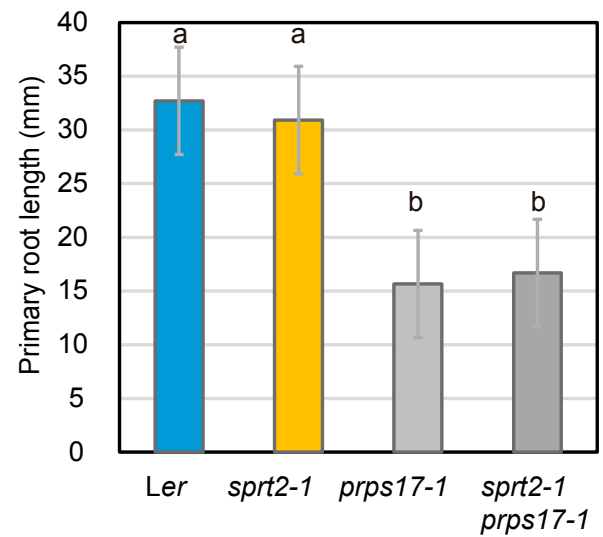

Figure 6. Effects of the sprt2-1 mutation on abnormal ribosome biogenesis. (a) Plants grown on 1/2 MS medium with $3 \%$ sucrose for $8 \mathrm{~d}$. Bar $=1 \mathrm{~cm}$. (b) PR lengths of seedlings at $8 \mathrm{dps}$. Data are means \pm SDs $(n=24)$. Statistical analysis was carried out by one-way ANOVA with Tukey HSD test $(p<0.05)$. Data without significant differences are labeled with the same letters. (c) PR lengths of Ler and sprt2-1 mutants treated with spectinomycin and grown for $8 \mathrm{~d}$. Data are means \pm SDs $(\mathrm{n} \geq 11)$ Asterisks $\left(^{*}\right)$ indicate significant differences $(p<0.05$, Student's t-test).

\subsection{Identification of the sprt2-1 Mutation Site}

To identify the causal gene in sprt2-1 mutants, we initially attempted a classical map-based approach. It was necessary to obtain an $r f c 3$ allele in the Colombia (Col) background to map the chromosomal location of the SPRT2 locus. We found two T-DNA insertion lines, $r f c 3-3$ and $r f c 3-4$, both of which were likely null alleles because RFC3 transcripts were almost undetectable (Figure S4a-c). However, $r f c 3-3$ and $r f c 3-4$ mutants produced normal LRs and shorter PRs (Figure S4d). F1 plants from a cross between $r f c 3-2$ and $r f c 3-3$ mutants produced normal LRs with short PRs (Figure S4d), suggesting a dominant modifier locus in the Col background. Because of this background effect, we abandoned this approach. We then carried out next-generation sequencing of $r f c 3-2$ sprt1-1 and $r f c 3-2$ sprt2-1 mutants. Extraction of $r f c 3-2$ sprt2-1-specific polymorphisms, compared to those of $r f c 3-2$ sprt1-1 mutants, and their mapping on corresponding chromosomal positions suggested that four single nucleotide polymorphisms (SNPs) were localized in an approximately 500-kb region of chromosome 4 (Figure 7a). We crossed $r f c 3-2$ sprt2-1 mutants with $r f c 3-2$ mutants and selected double-homozygous plants from their F2 progenies. Using the four SNPs as molecular markers, we found tight linkages between each of these SNPs and the SPRT2 locus (Figure 7a). Furthermore, one SNP showed complete linkage with the sprt2-1 mutant phenotype; it created a nonsense mutation in At4G14510, which encodes CFM3b (Figure $7 \mathrm{~b}, \mathrm{c}$ ). The defective protein was predicted to be truncated at the center of the first CRM domain (Figure 7b,c). RT-qPCR of $r f c 3-2$ sprt2-1 mutant showed that the CFM3b transcript levels tended to be slightly reduced, compared to the levels in WT plants; however, this difference was not statistically significant (Figure 7d). In another experiment, CFM3b expression was markedly reduced in $r f c 3-2$ sprt2-1 and sprt2-1 mutants (Figure 8a), suggesting that the mutated sprt2-1 transcripts underwent nonsense-mediated mRNA decay. CFM3b is a paralog of CFM3a that plays a role in the splicing of a subset of group IIB introns in plastids [23]. To examine whether CFM3b was the causal gene in sprt2-1 mutants, we introduced a WT copy of a CFM $3 b$ genomic fragment, translationally fused or not to GFP cDNA (pCFM3b::gCFM3b-GFP or pCFM3b::gCFM3b), into rfc3-2 sprt2-1 mutants. RT-qPCR 
confirmed that the expression of CFM3b was increased in these lines (Figure 7d). As expected, these transgenic lines produced shorter PRs with abnormal LRs, as observed in $r f c 3-2$ mutants (Figure 7e,f). Therefore, the results indicated that SPRT2 corresponds to CFM $3 b$ (At4g14510). Sequencing of the CFM3b coding region in $r f c 3-2$ sprt1-1 and $r f c 3-2$ sprt3-1 mutants yielded no mutations.

(a)

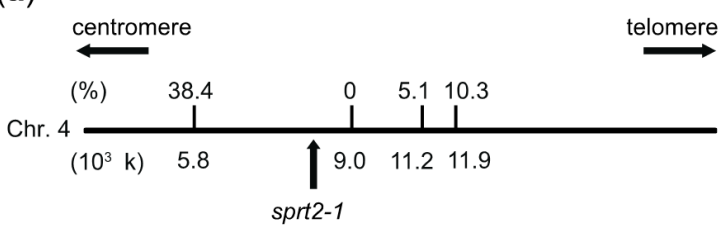

(c)

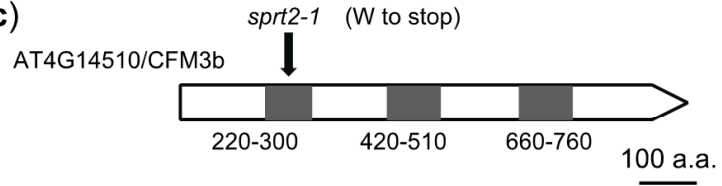

(b)

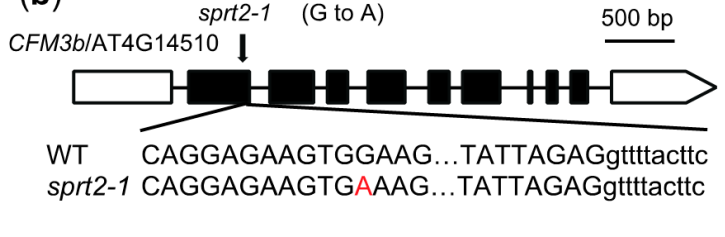

WT $\quad A \vee V D A I Q E K W K G S E$ sprt2-1 A $\vee \vee D A I Q E K$ Stop

(d)

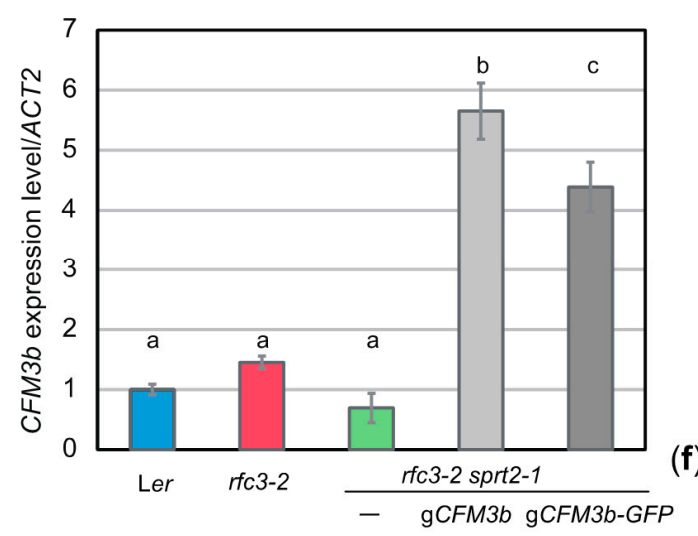

(e)

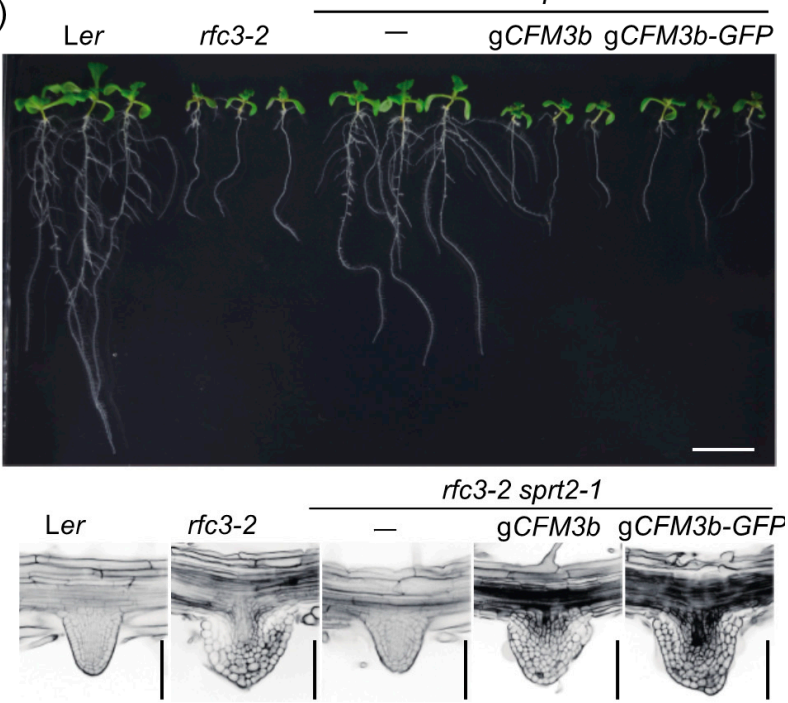

Figure 7. SPRT2 corresponds to CFM $3 b$ that encodes a chloroplast RNA splicing and ribosome maturation (CRM)-domain protein. (a) Genetic mapping of the sprt2-1 mutation site. A part of chromosome 4 is indicated by a bold line; nucleotide position is indicated below. Values on the bold line are recombination frequencies between single nucleotide polymorphisms and the sprt2-1 mutation site. (b) Gene structure of CFM3b (At4g14510). The mutation point of sprt2-1 is shown. (c) Protein structure of CFM3b. Gray boxes indicates CRM domains. The mutation point of sprt2-1 is shown. (d) CFM3b expression levels determined by RT-qPCR. Data are means \pm SDs. $(n=3)$. Statistical analysis was carried out by one-way ANOVA with Tukey HSD test $(p<0.05)$. Data without significant differences are labeled with the same letters. (e) Seedlings of sprt2-1 complementation lines. Plants were grown on $1 / 2$ MS medium containing 3\% sucrose for $11 \mathrm{~d}$. Bar $=1 \mathrm{~cm}$. (f) LR phenotypes of the complementation lines. Bars $=100 \mu \mathrm{m}$. 
(a)

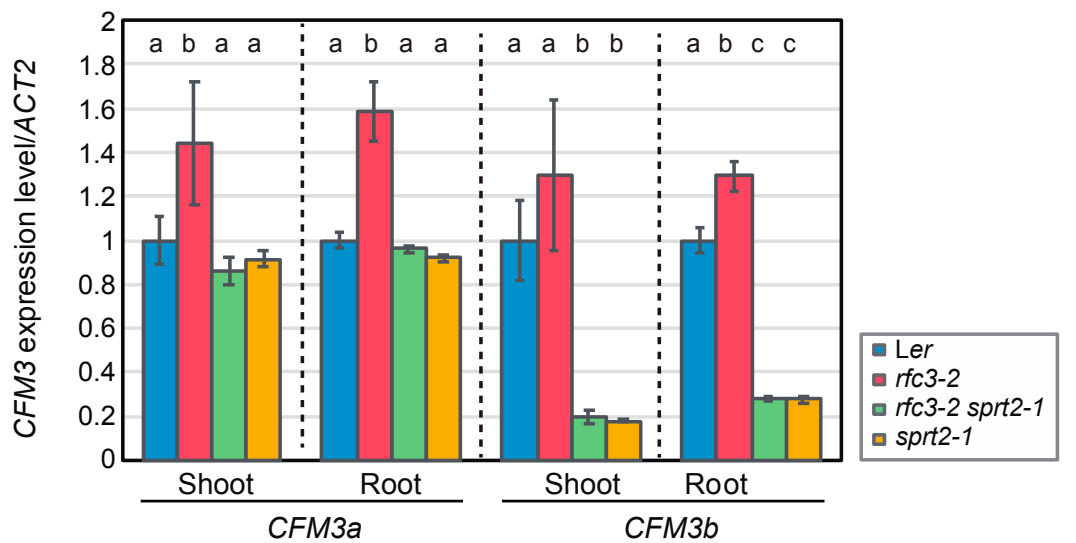

(b)

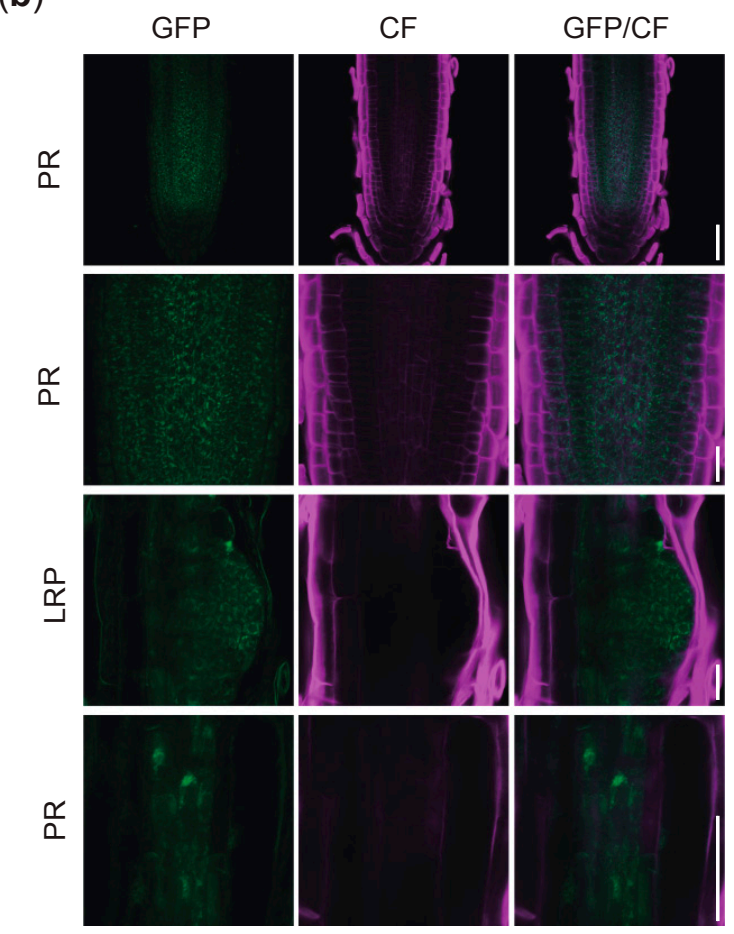

(c)
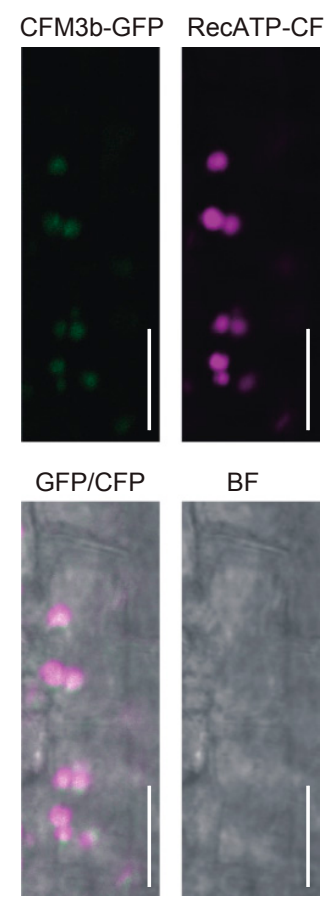

Figure 8. Expression level and pattern of CFM3b. (a) Expression levels of CFM $3 a$ and CFM $3 b$ in shoots and roots determined by RT-qPCR and normalized with ACT2 expression level. Data are means \pm SDs $(\mathrm{n}=3)$. Statistical analysis was carried out by one-way ANOVA with Tukey HSD test $(p<0.05)$ separately for shoot and root samples. Data without significant differences are labeled with the same letters. (b) Expression patterns of pCFM3b::gCFM3b-GFP in root apical meristem (RAM) of PR and LRP of $r f c 3-2$ sprt2-1 mutants. Bars $=50 \mu \mathrm{m}$ (top and bottom), $20 \mu \mathrm{m}$ (middle). Cell wall was stained by calcofluor white (CF). (c). Colocalization analysis of CFM3b-GFP and RecATP-CFP in lateral root cap cells of PR. Bars $=10 \mu \mathrm{m}$.

\subsection{Expression Pattern of CFM3b and Subcellular Localization of its Product}

We examined expression levels of CFM3a and CFM3b in $r f c 3-2, r f c 3-2$ sprt2-1, and sprt2-1 mutants. We noted that CFM3a exhibited elevated expression in $r f c 3-2$ mutant shoots and roots, compared to the shoots and roots of WT plants (Figure 8a). Similarly, CFM3b expression level in $r f c 3-2$ roots was slightly higher than the levels in WT roots although such a difference was not statistically significant in shoots (Figure 8a). In contrast, CFM3a expression levels in $r f c 3-2$ sprt2-1 and sprt2-1 mutants were similar to those in WT plants (Figure 8a). Therefore, the findings indicated that CFM $3 a$ and CFM $3 b$ are positively regulated by a defect caused by the $r f c 3-2$ mutation. CFM3b expression levels in $r f c 3-2$ sprt2-1 and sprt2-1 mutants were reduced compared those in WT plants (Figure 8a). We next examined the 
expression pattern of CFM $3 b$ and localization of the CFM3b protein using pCFM $3 b:: \mathrm{gCFM} 3 b-G F P / r f c 3-2$ sprt2-1 plants. CFM3b-GFP was very weakly expressed throughout the roots (Figure $8 \mathrm{~b}$ ), suggesting that the CMF3b mRNA level was low and/or that CFM3b protein was unstable. At the subcellular level, CFM3b-GFP fluorescence was observed in the form of many small dots with structures in cells of the primary RAM and LRPs (Figure $8 b$ ). Colocalization analysis was performed by crossing a p35S::RecATP-CFP reporter [35] and a pCFM3b::gCFM3b-GFP in the $r f c 3-2$ sprt2-1 background. The fluorescence signals of CFP and GFP merged in cells of the RAM (Figure 8c). These results suggested that CFM3b was localized to root plastids. In a previous study, GFP fused to the transit peptide of CFM3b localized to plastids when transiently expressed in onion epidermal cells [23]; this finding is consistent with the above results.

\subsection{RFC3 Interacts with CFM3b in Plastids}

Because both RFC3 and CFM3b localized to root plastids (Figure 8) [23,35], we analyzed whether RFC3 and CFM3b interacted with each other. We examined this possibility by yeast two-hybrid analysis and coimmunoprecipitation assays in Nicotiana benthamiana leaves. However, both attempts were unsuccessful; CFM3b-GFP was not detectable by Western blotting, even in input samples, despite expression of the fusion gene driven by the 35S promoter (data not shown). Next, RFC3-GFP and CFM3b-GFP were each transiently expressed in N. benthamiana leaves. A strong RFC3-GFP signal was observed in most pavement cells; however, a CFM3b-GFP signal was only observed occasionally (Figure 9a, right panel). Closer inspection indicated that both fusion proteins were localized in plastids (Figure 9a, left panel).

(a)

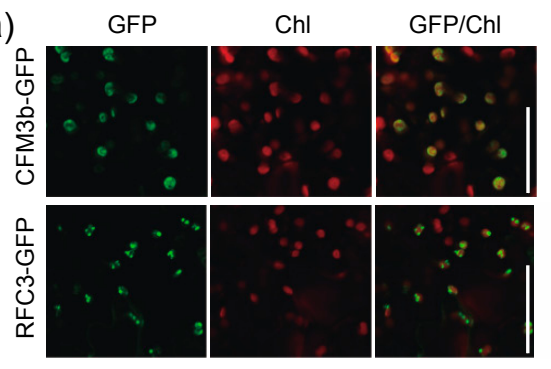

(b)

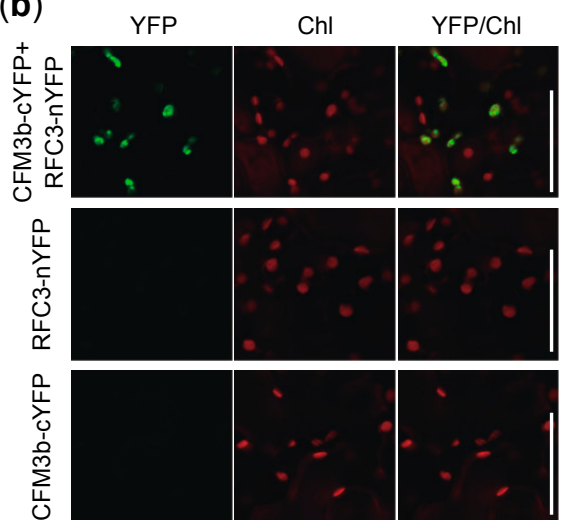

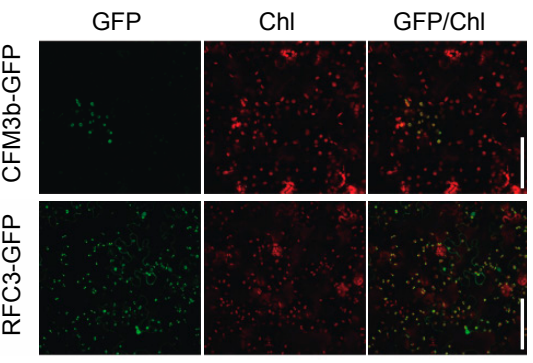

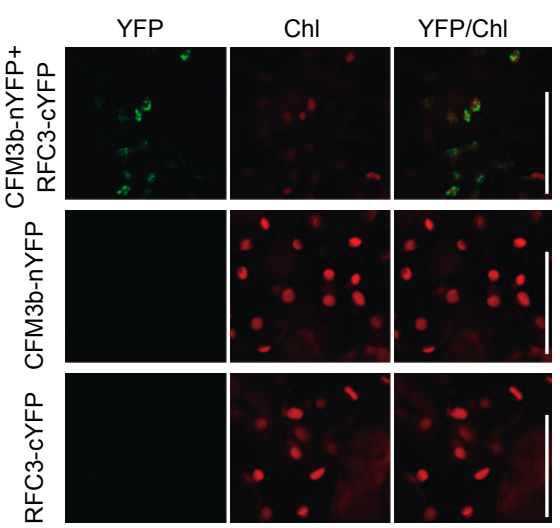

Figure 9. Cellular localization and bimolecular fluorescence complementation (BiFC) analysis of RFC3 and CFM3b. (a) RFC3 and CFM3b localization in plastids. RFC3-GFP and CFM3b-GFP were transiently expressed in N. benthamiana leaves. Bars in left and right panels indicate 50 and $100 \mu \mathrm{m}$, respectively. (b) BiFC analysis of RFC3 and CFM3b. Fluorescence resulting from complementation of the N-terminal part of YELLOW FLUORESCENT PROTEIN (YFP) fused with RFC3 (RFC3-nYFP) or CFM3b (CFM3b-nYFP) and the C-terminal part of YFP fused with CFM3b (CFM3b-cYFP) or RFC3 (RFC3-cYFP) were observed in epidermal cells of $N$. benthamiana leaves. Chl indicates chlorophyll autofluorescence. Bars $=50 \mu \mathrm{m}$. 
Next, we performed bimolecular fluorescence complementation (BiFC) analysis using $N$. benthamiana leaves. The N- or C-terminal part of a YELLOW FLUORESCENT PROTEIN (YFP) fragment (nYFP or cYFP) was fused to the C-terminal end of RFC3 and CFM3b; the fusion proteins were transiently expressed individually or in combination in N. benthamiana leaves. YFP fluorescence was reconstituted in plastids of epidermal cells when CFM3b-cYFP and RFC3-nYFP were coexpressed, as well as when CFM3b-nYFP and RFC3-cYFP were coexpressed (Figure 9b). No fluorescence signal was observed when each fusion protein was expressed alone (Figure $9 \mathrm{~b}$ ). These results suggested that RFC3 and CFM3b interact with each other in plastids.

\section{Discussion}

The molecular function of RFC3, a member of the bacterial RPS6 family, has been unclear because a bona fide PRPS6, which is phylogenetically related to cyanobacterial RPS6, is found in the 30S subunit $[4,35,46]$. Recently, a rice mutant, thermo-sensitive chlorophyll-deficient mutant11 (tcd11) was shown to be defective in an RFC3 ortholog [47]. TCD11 was reported to be a plastid RP, but supporting biochemical evidence is lacking [47]. Interestingly, several ribosomal protein homologs act as ribosome biogenesis factors during cytosolic ribosome biogenesis in Saccharomyces cerevisiae (yeast) [48]. In addition, $r f c 3$ mutants had significantly reduced levels of $16 \mathrm{~S}$ and $23 \mathrm{~S}$ rRNAs (Figure 5) [35]. Based on these lines of circumstantial evidence, we hypothesized that RFC3 has an extra-ribosomal function, potentially in the biogenesis and/or stabilization of plastid rRNA. To gain insight into the molecular function of RFC3, we isolated suppressor mutants of the $r f c 3-2$ phenotype and found that CFM $3 b$ is the causal gene for the sprt2 phenotype.

CFM3b is a paralog of the group II intron splicing factor CFM3a [23]. Because BiFC assays suggested that RFC3 and CFM3b interact in plastids and the sprt2-1 mutation recovered the reduced plastid rRNA level in $r f c 3-2$ mutants, these two proteins likely directly or indirectly influence the rRNA level in plastids. Failure of the sprt2-1 mutation to recover the spectinomycin- or prps17 mutation-induced PR growth defect suggests that the sprt2-1 mutation specifically affects a pathway in which RFC3 plays an important role in the maintenance of a sufficient plastid rRNA level. Therefore, it is feasible that nearly all aspects of $r f c 3-2$ mutant phenotypes were recovered by the sprt2-1 mutation.

A number of mutants defective in plastid rRNA accumulation have been reported. These mutants can be classified into two groups based on the patterns of changes in rRNA levels. The first group is associated with specific or preferential reduction of rRNAs in the $30 \mathrm{~S}$ or $50 \mathrm{~S}$ subunit. For example, Arabidopsis mutants defective in a $30 \mathrm{~S}$ ribosomal protein (i.e., prps5, prps17, and plastid-specific ribosomal protein4 [psrp4]) [45,49,50], and a 50S ribosomal protein (i.e., prpl6/embryo defective2394 [emb2394], prpl24/suppressor of variegation8 [svr8], and psrp5) [45,50-52] exhibit reduced levels of $16 \mathrm{~S}$ and $23 \mathrm{~S}$ rRNAs, respectively. Similarly, mutants defective in some ribosome biogenesis factors show reduced levels of mature $16 \mathrm{~S}$ rRNA (rap and rbfa domain-containing protein 1 [rbf1]) [53,54] and mature $23 \mathrm{~S}$ rRNA (svr7) [55], respectively.

The second group shows general reductions in the levels of plastid rRNAs. This group includes a wide range of plastid proteins, as well as $r f c 3$ mutants. prps 21 is a viable mutant with a relatively strong defect in shoot growth and has reduced levels of $16 \mathrm{~S}$ and $23 \mathrm{~S}$ rRNAs [56]. Similarly, co-suppression lines of PRPL15 in Arabidopsis and a knockout line of prps15 in tobacco have shown reductions in $16 \mathrm{~S}$ and $23 \mathrm{~S}$ rRNA levels $[57,58]$. PALE CRESS (PAC) binds to $23 \mathrm{~S}$ rRNA and promotes $50 \mathrm{~S}$ subunit biogenesis, while the pac mutants dramatically reduce levels of both $16 \mathrm{~S}$ and $23 \mathrm{~S}$ rRNAs [59]. SUPPRESSOR OF THYLAKOID FORMATION1 (SOT1) binds the $5^{\prime}$ end of $23 \mathrm{~S}$ and $4.5 \mathrm{~S}$ rRNA precursors, whereas the sot 1 mutants reduce the levels of 23S, 4.5S, 16S, and $5 \mathrm{~S}$ rRNAs [60]. In addition, mutants defective in translocon (translocon at the inner envelope membrane of chloroplasts56 [tic56] and plastid protein import2 [ppi2]) [61], transcription (plastid transcriptionally active chromosome3 [ptac3]) [62], translation (svr3 and mitochondrial transcription termination factor6 [mterf6]) [63,64], splicing (sot5) [65], and RNA editing (early chloroplast development1 [ecd1]) [66] show reduced levels of $16 \mathrm{~S}$ and $23 \mathrm{~S}$ rRNAs. These phenotypes are likely related to the inability to translate plastid-encoded ribosomal proteins. Indeed, treatment of WT 
plants with the plastid-translation inhibitors lincomycin [59] and spectinomycin [35] results in reduced levels of $16 \mathrm{~S}$ and $23 \mathrm{~S}$ rRNAs. In contrast, YbeY and RNR1 are involved in maturation of the termini of multiple rRNA species; mutations of these proteins result in markedly reduced levels of $16 \mathrm{~S}$ and $23 \mathrm{~S}$ rRNAs $[67,68]$. Therefore, reduced levels of $16 \mathrm{~S}$ and $23 \mathrm{~S}$ rRNAs can result from defects in (i) ribosome biogenesis factors broadly involved in $30 \mathrm{~S}$ and $50 \mathrm{~S}$ biogenesis; (ii) those specifically involved in $30 \mathrm{~S}$ or $50 \mathrm{~S}$ biogenesis; or (iii) plastid proteins not directly involved in ribosome biogenesis, although they secondary impair translation in plastids.

$r f c 3$ likely belongs to one of the above three categories. With regard to rRNA processing patterns, the levels of nearly all rRNA processing intermediates and mature $16 \mathrm{~S}$ and $23 \mathrm{~S}$ rRNAs in WT plants were markedly reduced in $r f c 3$ mutants; these defects were recovered by sprt 2 mutations. An exception was 3.0-kb precursors of $23 \mathrm{~S}$ rRNA, which exhibited overaccumulation in $r f c 3-2$ mutants; this finding was indicative of the rate-limiting step of rRNA processing in $r f c 3-2$ mutants. Interestingly, $r f c 3-2$ mutants exhibited reduction of the 16S rRNA level to a greater degree than that of the $23 \mathrm{~S}$ rRNA level, suggesting that RFC3 plays an additional role in the processing of $16 \mathrm{~S}$ rRNA precursors. Notably, only $r f c 3-2$ sprt2-1 mutants exhibited overaccumulation of 1.7-kb $16 \mathrm{~S}$ rRNA precursors, among all plant lines examined. If CFM $3 \mathrm{~b}$ affects rRNA levels in $r f c 3-2$ mutants, as a consequence of reduced plastid translation, $r f c 3-2$ sprt2-1 mutants should process 1.7-kb 16S rRNA intermediates normally; however, this phenomenon was not observed. These results suggest that (i) CFM3b likely affects one or more steps in rRNA processing or stability; (ii) RFC3 may prevent an unfavorable effect of CFM3b on rRNA processing; and (iii) RFC3 may also be involved in the processing of $1.7-\mathrm{kb} 16 \mathrm{~S}$ rRNA precursors.

Consistent with the results of an earlier report that did not found visible $c f m 3 b$ phenotypes [23], sprt2-1 single mutants also showed an almost normal rRNA processing pattern, suggesting that CFM $3 \mathrm{~b}$ plays only a minor role in WT plants. In contrast, sprt2-1 mutants exhibited recovery of the reduction in rRNA levels observed in $r f c 3-2$ mutants. Therefore, RFC3 contributes to plastid rRNA biosynthesis through suppression of the non-specific actions of CFM3b. From a broader perspective, the role of CRM domain proteins in RNA metabolism requires specific RNA conformations. For example, CRS1 facilitates folding of the group II intron of atpF [16]. The RNA chaperone activity CFM4 complements the lack of such activity in an E. coli strain [27]. Furthermore, CFM3a plays distinct roles in plastids and mitochondria: It promotes group IIB intron splicing and is involved in mitochondrial $18 \mathrm{~S}$ rRNA processing, respectively [23]. These examples suggest that CRM domains can interact with distinct RNA species with complex structures. In the absence of RFC3, CFM3b may directly or indirectly inhibit processing of rRNA. Because RFC3 and CFM3b interact with each other, RFC3 may sequester CFM3b to prevent its interactions with non-client RNAs. In such a case, RFC3 has a role to ensure the accuracy of RNA metabolism in plastids. A second possibility is that a potential defect in group IIB intron splicing by the sprt2-1 mutation promotes rRNA processing and/or stability. Among the suggested targets of CFM3 [23], $n d h B$, petB, and petD encodes proteins involved in photosynthetic electron transport and therefore do not have a direct link with rRNA biogenesis. The remaining targets of CFM3 encode ribosomal proteins ( $r p l 16$ and $r p s 16)$ and a tRNA $(t r n G)$. If their splicing is impaired, rRNA biogenesis is expected to be negatively affected, but this is the opposite of what we observed and therefore this possibility is unlikely.

There are several examples of mutations or genetic manipulations that suppress the phenotypes caused by defects in ribosome biogenesis. For example, in yeast $40 \mathrm{~S}$ ribosome biogenesis, depletion of Rio1 inhibits 20S rRNA cleavage and results in a lethal phenotype; however, this can be bypassed by missense mutations of Nob1 and Pno1 [69]. Similarly, the lethal phenotype of a mutant defective in yeast $60 \mathrm{~S}$ ribosome biogenesis factor Nsa1 can be suppressed by mutations in Mak5, Nop1, and Nop4 [70]. These and other studies reveal the existence of multiple checkpoints in ribosome assembly pathways $[69,71]$. A pioneering work showed that the expression of a dominant-negative form of ribosome biogenesis factor Bop1 inhibits ribosome biogenesis and causes cell cycle arrest in cultured mouse cells; this cell cycle arrest could be avoided by inactivation of p53 [72]. A number of subsequent works established the ribosome stress response pathway, in which defects in ribosome biogenesis 
induce an interaction between RPs and the E3 ubiquitin ligase MDM2, then stabilize p53, a master regulator of the stress response; this interaction induces cell cycle arrest [73]. Although plants do not have homologs of MDM2 or p53, a ribosome stress response pathway is present in Arabidopsis [74,75]. A suppressor screening of a ribosome biogenesis mutant, root initiation defective2 (rid2), showed that suppressor of rid two1 (sriw1) disrupted the NAC transcription factor gene ANAC082 [74]. In rid2 sriw1 mutants, the growth defect of the rid2 phenotype was suppressed by the sriw1 mutation, without recovery of defective ribosome biogenesis [74]. Therefore, SRIW1 might share some common attributes with the animal p53 with regard to ribosome stress response pathway.

Given that suppressors of ribosome biogenesis mutants yielded important biological findings, the correlation between the plastid rRNA level and the LR developmental phenotype in $r f c 3-2$ and $r f c 3-2$ sprt2-1 mutants is noteworthy. This correlation suggests that impaired plastid rRNA biogenesis alters the expression patterns of nuclear-encoded genes involved in LR development. It remains unclear whether these changes are secondary to the general growth defect of the $r f c 3$ phenotype or represent a specific outcome of "plastid ribosome stress". The plastid-to-nucleus signaling pathways, termed retrograde signaling, have been extensively studied with a focus on chloroplast development and regulation of photosynthesis [76]. GENOMES UNCOUPLED1 (GUN1) is considered an integrator of signals in response to perturbations in the redox state, tetrapyrrole biosynthesis, and plastid gene expression [77]. Lincomycin is used to impair plastid gene expression and evoke GUN1-dependent retrograde signaling [77]. Interestingly, gun1 synergistically enhances the shoot growth defect when combined with prpl11, but not prps21 or prps1; moreover, GUN1 physically interacts with several RPs in plastids [56]. Concerning development, the leaf adaxial-abaxial boundary is destabilized by lincomycin treatment or by enhanced fil expression domain2 (enf2) mutations, which disrupt a plastid-localized PotD homolog [78]. Such destabilization of adaxal-abaxial boundary occurs in a GUN1-dependent manner [78]. In contrast, it is unknown whether GUN1 has a role in roots. The relationships among $r f c 3$, sprt2, and gun1 phenotypes are of particular interest and will be examined in a future study.

In summary, the bRPS6-family member RFC3 likely contributes to plastid rRNA biogenesis by preventing nonspecific effects of CFM3b, thereby enhancing the accuracy of RNA metabolism in plastids. In addition, the normal function of plastids is related to the development of LRs. The relationship between plastid function and LR formation will be elucidated by further biochemical analysis of functional relationships between RFC 3 and CFM3b, as well as identification of the responsible genes in other sprt mutants.

\section{Materials and Methods}

\subsection{Plant Materials and Growth Conditions}

WT plants used in this study were Ler and Col-0. Alleles of $r f c 3$ were described previously $(r f c 3-2)$ [34] or obtained from the Arabidopsis Biological Resource Center (rfc3-3 [Salk_015990] and rfc3-4 [Sail_557_D02]). pWOX5::GFP [79], pPLT3::CFP [44,80], QC25::GUS and QC184::GUS [81], p35S::RecATP-CFP [35], and prps17-1 [45] were reported previously. The reporter lines or mutants were introgressed into the Ler background by at least four successive genetic crosses. Plants were cultured under long-day conditions ( $16 \mathrm{~h} \mathrm{light,} 8 \mathrm{~h}$ dark) at $22^{\circ} \mathrm{C}$. The light intensity was 50 or 20 $\mu \mathrm{mol} \mathrm{m} \mathrm{m}^{-2} \mathrm{~s}^{-1}$ when rock wool or solid medium was used, respectively. Half-strength Murashige and Skoog (MS) medium [82] supplemented with $3 \%$ or $2 \%(\mathrm{w} / \mathrm{v})$ sucrose and solidified with $0.5 \%$ $(w / v)$ gellan gum was used to observe root phenotypes. Spectinomycin (Wako Pure Chemical, Osaka, Japan) was added to MS medium at final concentrations up to $6 \mathrm{mg} / \mathrm{L}$ as a plastid ribosome inhibitor. Plants were grown on rock wool covered with powdered peat moss to observe shoot phenotypes or to generate transgenic plants. N. benthamiana was grown on peat containing nutrients (Sakatanotane Co., Yokohama, Japan) and Arabidopsis was grown with $0.5 \mathrm{~g} / \mathrm{L}$ Hyponex (Hyponex Japan, Osaka, Japan) supplied daily as fertilizer. 


\subsection{Isolation of Suppressor Mutants of $r f c 3-2$}

Mutagenesis was carried out by incubating approximately $10,000 \mathrm{rfc} 3-2$ seeds in 0.1 to $0.3 \%(\mathrm{v} / \mathrm{v})$ ethyl methanesulfonate solution for $16 \mathrm{~h}$. Three suppressor lines were identified by visual inspection of LRs in approximately 10,000 M2 seedlings. These suppressors were crossed with $r f c 3-2$ mutants three times before use in experiments.

\subsection{Genetic Mapping of the sprt2-1 Mutation Site}

Genomic DNA was extracted for resequencing of $r f c 3-2$ sprt1-1 and $r f c 3-2$ sprt2-1 mutants and for genetic mapping of the sprt2-1 mutation site according to [83] with an additional extraction step with phenol:chloroform:isoamylalcohol (25:24:1). The genomic DNA of $r f c 3-2$ sprt1-1 and $r f c 3-2$ sprt2-1 mutants was subjected to paired-end sequencing on a HiSeq 2500 (Illumina, San Diego, CA, USA) at Hokkaido System Science Co., Ltd. (Sapporo, Japan). G to A and C to T transversions were identified and sprt2-1-specific changes were recovered. $r f c 3-2$ sprt2-1 segregants in an F2 population, obtained from a cross between $r f c 3-2$ sprt2-1 and $r f c 3-2$ mutants, were used for genetic mapping. The mutation point of sprt2-1 was localized using the polymorphisms between $r f c 3-2$ sprt2-1 and $r f c 3-2$ mutants as genetic markers.

\subsection{Complementation Test of sprt2}

CFM3b genomic fragments containing an approximately 1.4-kb promoter region and the transcribed region, with or without the termination codon, were amplified by polymerase chain reaction (PCR) and cloned into pENTR/D-TOPO (Thermo Fisher Scientific, Rockford, IL, USA). Next, the CFM3b sequences were transferred into the binary vectors pBG [84] and pHWG [85], respectively, using Gateway LR clonase II (Thermo Fisher Scientific, Walham, MA, USA). rfc3-2 sprt2-1 mutant plants were transformed with these vectors by the floral-dip method [86]. Homozygous plants with a single T-DNA insertion were used in experiments.

\subsection{Microscopy}

Structure of LRPs was observed in detail by the pseudo-Schiff-propidium iodide (mPS-PI) method, as described previously with some modifications [35,87]. LRPs were observed using an LSM 800 microscope (Carl Zeiss, Zena, Germany). Roots of QC25::GUS and QC184::GUS lines were submerged in ice-cooled $90 \%(\mathrm{v} / \mathrm{v})$ acetone for fixation, then incubated in $\beta$-glucuronidase (GUS) reaction solution (500 $\mu \mathrm{g} / \mathrm{mL}$ 5-bromo-4-chloro-3-indolyl- $\beta$-D-glucuronic acid, $100 \mathrm{mM} \mathrm{NaPO}_{4}$ [pH 7], $3 \mathrm{mM}$ potassium ferricyanide, $10 \mathrm{mM}$ EDTA, $0.1 \%$ [v/v] Triton X-100) overnight at $37^{\circ} \mathrm{C}$ for GUS staining. The roots were cleared with chloral hydrate solution [84] and observed under a DM2500 microscope equipped with a DFC420C camera (Leica Microsystems, Wetzlar, Germany). Plants were grown in 1/2 MS medium containing $3 \%(\mathrm{w} / \mathrm{v})$ sucrose for 3 weeks and chlorophyll autofluorescence was observed using an LSM 800 microscope. pWOX5::GFP, pPLT3::CFP, p35S::RecATP-CFP lines stained with or without $10 \mu \mathrm{g} / \mathrm{mL}$ propidium iodide (PI) were observed by LSM800. pCFM3b::gCFM3b-GFP line was fixed, stained with Calcofluor White and cleared according to [88], and observed by LSM800.

\subsection{Transient Assays}

Transient assays in N. benthamiana were carried out according to [89,90]. RFC3 and CFM $3 b$ cDNAs without the termination codon were cloned into $\mathrm{pENTR/D} \mathrm{TOPO}$, using the primers in Table S1. Next, the inserts were transferred into $\mathrm{pB} 4 \mathrm{GWnY}, \mathrm{pB} 4 \mathrm{GWcY}$, or $\mathrm{pH} 35 \mathrm{WG}$ vectors carrying $\mathrm{N}$ - and C-terminal parts of YFP or full-length GFP, respectively, by LR clonase $[35,91]$. These constructs were introduced into Agrobacterium tumefaciens $\mathrm{C} 58 \mathrm{C} 1$ by electroporation. A. tumefaciens were cultured, collected by centrifugation, diluted with $\mathrm{dH}_{2} \mathrm{O}$ to an $\mathrm{A}_{600}$ of 0.8 , and mixed with acetosyringone (final concentration of $150 \mu \mathrm{M})$. The A. tumefaciens solution was infiltrated into 4-5-week-old leaves of $N$. benthamiana 
using a syringe without a needle. N. benthamiana plants were grown for 2-3 days and the leaves were harvested. Leaf mesophyll and epidermal cells were observed by LSM800.

\subsection{Northern Blot Analysis of Plastid rRNAs}

Total RNAs were extracted from roots of 8-day-old seedlings grown on half-strength MS agar supplemented with 3\% (w/v) sucrose using TRI regent (Merck, Darmstadt, Germany) according to the manufacturer's instructions. Total RNA was separated on a $2 \%(\mathrm{w} / \mathrm{v})$ agarose gel containing formaldehyde and transferred to a positively charged nylon membrane (Merck) by capillary transfer. Template DNAs for in vitro transcription were amplified by PCR using specific primers (Table S1) and DIG-labeled RNA probes were synthesized using the DIG Northern Starter Kit or DIG RNA Labeling Kit (Roche, Basel, Switzerland). The membranes were hybridized with DIG-labeled RNA probes and washed; hybridization signals were detected using an ImageQuant LAS 4000mini instrument (GE Healthcare, Chicago, IL, USA), in accordance with the manufacturer's instructions.

\section{8. $R T-q P C R$}

Seedlings grown on half-strength MS agar supplemented with 3\% (w/v) sucrose for $11 \mathrm{~d}$ and whole seedlings, shoots, or roots were frozen in liquid nitrogen; total RNA was extracted with TRI reagent (Merck), in accordance with the manufacturer's instructions. After DNase I treatment, 2 $\mu \mathrm{g}$ of total RNA were subjected to RT-PCR using the SuperScript III First-Strand System (Thermo Fisher Scientific). Oligo (dT) primers were used to amplify mRNAs from nuclear-encoded genes; random hexamers were used to amplify mRNAs from plastid-encoded gene and cytoplasmic rRNAs. Quantitative PCR was performed with Go Taq qPCR Master Mix (Promega, Madison, WI, USA) using the QuantStudio ${ }^{\mathrm{TM}}$ 12K Flex Real-Time PCR System (Thermo Fisher Scientific). The expression levels of nuclear- and plastid-encoded genes were calculated by the $\Delta \Delta \mathrm{CT}$ method [92] and normalized to ACT2 and 18S rRNA, respectively. Primers are listed in Table S1.

Supplementary Materials: The following are available online at http://www.mdpi.com/2223-7747/9/3/328/s1, Figure S1: Root phenotypes of homozygous and heterozygous sprt mutants grown on a half-strength of MS medium supplemented with $2 \%$ (w/v) sucrose, Figure S2: Expression of pWOX5::GFP in later-stage LRs, Figure S3: Expression of QC184 marker, Figure S4: Effect of genetic background on lateral root phenotype, according to $r f c 3$ alleles, Table S1: Information of primers used in this study.

Author Contributions: Conceptualization, G.H.; methodology, G.H., M.T.N., and S.M.; validation, G.H., S.M., and Y.N.; formal analysis, G.H. and Y.N.; investigation, A.I., G.H., K.O., M.T.N., S.M., and Y.N.; resources, G.H., M.T.N., and M.S.; writing — original draft preparation, Y.N.; writing_-review and editing, G.H. and S.M.; visualization, Y.N.; supervision, G.H. and S.M.; project administration, G.H.; funding acquisition, G.H. All authors have read and agreed to the final version of the manuscript.

Funding: This work was supported by JSPS KAKENHI Grant Number JP19K06714.

Acknowledgments: We thank T. Nakagawa (Shimane University), H. Ichikawa (NARO), S. Mano (NIBB), and K. Mise (Kyoto University) for providing the vectors; B. Scheres (Wageningen University) for providing reporter lines; S. Nakamura for her contribution during the early phase of this study; and M. Kagami for technical assistance.

Conflicts of Interest: The authors declare no conflict of interest. The funders had no role in the design of the study; in the collection, analyses, or interpretation of data; in the writing of the manuscript, or in the decision to publish the results.

\section{References}

1. Andersson, S.G.E.; Karlberg, O.; Canbäck, B.; Kurland, C.G. On the origin of mitochondria: A genomics perspective. Phil. Trans. R. Soc. Lond. B 2003, 358, 165-179. [CrossRef] [PubMed]

2. Raven, J.A.; Allen, J.F. Genomics and chloroplast evolution: What did cyanobacteria do for plants? Genome Biol. 2003, 4, 209. [CrossRef] [PubMed]

3. Harris, E.H.; Boynton, J.E.; Gillham, N.W. Chloroplast ribosomes and protein synthesis. Microbiol. Rev. 1994, 58, 700-754. [CrossRef] [PubMed] 
4. Yamaguchi, K.; von Knoblauch, K.; Subramanian, A.R. The plastid ribosomal proteins. Identification of all the proteins in the $30 \mathrm{~S}$ subunit of an organelle ribosome (chloroplast). J. Biol. Chem. 2000, 275, 28455-28465. [CrossRef] [PubMed]

5. Yamaguchi, K.; Subramanian, A.R. The plastid ribosomal proteins. Identification of all the proteins in the 50 $\mathrm{S}$ subunit of an organelle ribosome (chloroplast). J. Biol. Chem. 2000, 275, 28466-28482. [CrossRef] [PubMed]

6. Yamaguchi, K.; Subramanian, A.R. Proteomic identification of all plastid-specific ribosomal proteins in higher plant chloroplast 30 S ribosomal subunit. Eur. J. Biochem. 2003, 270, 190-205. [CrossRef]

7. Tiller, N.; Bock, R. The translational apparatus of plastids and its role in plant development. Mol. Plant 2014, 7, 1105-1120. [CrossRef]

8. Wakasugi, T.; Tsudzuki, T.; Sugiura, M. The genomics of land plant chloroplasts: Gene content and alteration of genomic information by RNA editing. Photosynth. Res. 2001, 70, 107-118. [CrossRef]

9. Stern, D.B.; Goldschmidt-Clermont, M.; Hanson, M.R. Chloroplast RNA metabolism. Annu. Rev. Plant Biol. 2010, 61, 125-155. [CrossRef]

10. Germain, A.; Hotto, A.M.; Barkan, A.; Stern, D.B. RNA processing and decay in plastids. WIREs RNA 2013, 4, 295-316. [CrossRef]

11. Sun, L.; Xu, Y.; Bai, S.; Bai, X.; Zhu, H.; Dong, H.; Wang, W.; Zhu, X.; Hao, F.; Song, C.P. Transcriptome-wide analysis of pseudouridylation of mRNA and non-coding RNAs in Arabidopsis. J. Exp. Bot. 2019, 70, 5089-5100. [CrossRef] [PubMed]

12. Wang, Z.; Tang, K.; Zhang, D.; Wan, Y.; Wen, Y.; Lu, Q.; Wang, L. High-throughput $\mathrm{m}^{6}$ A-seq reveals RNA $\mathrm{m}^{6} \mathrm{~A}$ methylation patterns in the chloroplast and mitochondria transcriptomes of Arabidopsis thaliana. PLoS ONE 2017, 12, e0185612. [CrossRef] [PubMed]

13. Burgess, A.L.; David, R.; Searle, I.R. Conservation of tRNA and rRNA 5-methylcytosine in the kingdom Plantae. BMC Plant Biol. 2015, 15, 199. [CrossRef] [PubMed]

14. Nishimura, K.; Ashida, H.; Ogawa, T.; Yokota, A. A DEAD box protein is required for formation of a hidden break in Arabidopsis chloroplast 23S rRNA. Plant J. 2010, 63, 766-777. [CrossRef] [PubMed]

15. Bonen, L.; Vogel, J. The ins and outs of group II introns. Trends Genet. 2001, 17, 322-331. [CrossRef]

16. Ostersetzer, O.; Cooke, A.M.; Watkins, K.P.; Barkan, A. CRS1, a chloroplast group II intron splicing factor, promotes intron folding through specific interactions with two intron domains. Plant Cell 2005, 17, 241-255. [CrossRef]

17. De Longevialle, A.F.; Small, I.D.; Lurin, C. Nuclearly encoded splicing factors implicated in RNA splicing in higher plant organelles. Mol. Plant 2010, 3, 691-705. [CrossRef]

18. Barkan, A.; Klipcan, L.; Ostersetzer, O.; Kawamura, T.; Asakura, Y.; Watkins, K.P. The CRM domain: An RNA binding module derived from an ancient ribosome-associated protein. RNA 2007, 13, 55-64. [CrossRef]

19. Gagarinova, A.; Stewart, G.; Samanfar, B.; Phanse, S.; White, C.A.; Aoki, H.; Deineko, V.; Beloglazova, N.; Yakunin, A.F.; Golshani, A.; et al. Systematic genetic screens reveal the dynamic global functional organization of the bacterial translation machinery. Cell Rep. 2016, 17, 904-916. [CrossRef]

20. Ostheimer, G.J.; Williams-Carrier, R.; Belcher, S.; Osborne, E.; Gierke, J.; Barkan, A. Group II intron splicing factors derived by diversification of an ancient RNA-binding domain. EMBO J. 2003, 22, 3919-3929. [CrossRef]

21. Jenkins, B.D.; Barkan, A. Recruitment of a peptidyl-tRNA hydrolase as a facilitator of group II intron splicing in chloroplasts. EMBO J. 2001, 20, 872-879. [CrossRef] [PubMed]

22. Till, B.; Schmitz-Linneweber, C.; Williams-Carrier, R.; Barkan, A. CRS1 is a novel group II intron splicing factor that was derived from a domain of ancient origin. RNA 2001, 7, 1227-1238. [CrossRef] [PubMed]

23. Asakura, Y.; Bayraktar, O.A.; Barkan, A. Two CRM protein subfamilies cooperate in the splicing of group IIB introns in chloroplasts. RNA 2008, 14, 2319-2332. [CrossRef] [PubMed]

24. Asakura, Y.; Barkan, A. A CRM domain protein functions dually in group I and group II intron splicing in land plant chloroplasts. Plant Cell 2007, 19, 3864-3875. [CrossRef]

25. Zmudjak, M.; des Francs-Small, C.C.; Keren, I.; Shaya, F.; Belausov, E.; Small, I.; Ostersetzer-Biran, O. mCSF1, a nucleus-encoded CRM protein required for the processing of many mitochondrial introns, is involved in the biogenesis of respiratory complexes I and IV in Arabidopsis. New Phytol. 2013, 199, 379-394. [CrossRef]

26. Lee, K.; Park, S.J.; Park, Y.I.; Kang, H. CFM9, a mitochondrial CRM protein, is crucial for mitochondrial intron splicing, mitochondria function and Arabidopsis growth and stress responses. Plant Cell Physiol. 2019, 60, 2538-2549. [CrossRef] 
27. Lee, K.; Lee, H.J.; Kim, D.H.; Jeon, Y.; Pai, H.S.; Kang, H. A nuclear-encoded chloroplast protein harboring a single CRM domain plays an important role in the Arabidopsis growth and stress response. BMC Plant Biol. 2014, 14, 98. [CrossRef]

28. Sakamoto, W.; Miyagishima, S.; Jarvis, P. Chloroplast biogenesis: Control of plastid development, protein import, division and inheritance. Arab. Book 2008, 6, e0110. [CrossRef]

29. Waters, M.T.; Langdale, J.A. The making of a chloroplast. EMBO J. 2009, 28, 2861-2873. [CrossRef]

30. Kobayashi, K.; Baba, S.; Obayashi, T.; Sato, M.; Toyooka, K.; Keränen, M.; Aro, E.M.; Fukaki, H.; Ohta, H.; Sugimoto, K.; et al. Regulation of root greening by light and auxin/cytokinin signaling in Arabidopsis. Plant Cell 2012, 24, 1081-1095. [CrossRef]

31. Pyke, K.A.; Page, A.M. Plastid ontogeny during petal development in Arabidopsis. Plant Physiol. 1998, 116, 797-803. [CrossRef]

32. Bramham, L.; Pyke, K. Changing plastid dynamics within early root and shoot apical meristem-derived tissue of A. thaliana. Biosci. Horizons 2017, 10, hz002. [CrossRef]

33. Horiguchi, G.; Kodama, H.; Iba, K. Characterization of Arabidopsis mutants that are associated with altered C18 unsaturated fatty acid metabolism. Plant Sci. 2001, 161, 1117-1123. [CrossRef]

34. Horiguchi, G.; Kodama, H.; Iba, K. Mutations in a gene for plastid ribosomal protein S6-like protein reveal a novel developmental process required for the correct organization of lateral root meristem in Arabidopsis. Plant J. 2003, 33, 521-529. [CrossRef] [PubMed]

35. Nakata, M.T.; Sato, M.; Wakazaki, M.; Sato, N.; Kojima, K.; Sekine, A.; Nakamura, S.; Shikanai, T.; Toyooka, K.; Tsukaya, H.; et al. Plastid translation is essential for lateral root stem cell patterning in Arabidopsis thaliana. Biol. Open 2018, 7, bio028175. [CrossRef] [PubMed]

36. Malamy, J.E.; Benfey, P.N. Organization and cell differentiation in lateral roots of Arabidopsis thaliana. Development 1997, 124, 33-44. [PubMed]

37. Okushima, Y.; Fukaki, H.; Onoda, M.; Theologis, A.; Tasaka, M. ARF7 and ARF19 Regulate lateral root formation via direct activation of LBD/ASL genes in Arabidopsis. Plant Cell 2007, 19, 118-130. [CrossRef]

38. De Rybel, B.; Vassileva, V.; Parizot, B.; Demeulenaere, M.; Grunewald, W.; Audenaert, D.; Van Campenhout, J.; Overvoorde, P.; Jansen, L.; Vanneste, S.; et al. A novel Aux/IAA28 signaling cascade activates GATA23-dependent specification of lateral root founder cell identity. Curr. Biol. 2010, 20, 1697-1706. [CrossRef]

39. Goh, T.; Joi, S.; Mimura, T.; Fukaki, H. The establishment of asymmetry in Arabidopsis lateral root founder cells is regulated by LBD16/ASL18 and related LBD/ASL proteins. Development 2012, 139, 883-893. [CrossRef]

40. Du, Y.; Scheres, B. PLETHORA transcription factors orchestrate de novo organ patterning during Arabidopsis lateral root outgrowth. Proc. Natl. Acad. Sci. USA 2017, 114, 11709-11714. [CrossRef]

41. Goh, T.; Toyokura, K.; Wells, D.M.; Swarup, K.; Yamamoto, M.; Mimura, T.; Weijers, D.; Fukaki, H.; Laplaze, L.; Bennett, M.J.; et al. Quiescent center initiation in the Arabidopsis lateral root primordia is dependent on the SCARECROW transcription factor. Development 2016, 143, 3363-3371. [CrossRef] [PubMed]

42. Shimotohno, A.; Heidstra, R.; Blilou, I.; Scheres, B. Root stem cell niche organizer specification by molecular convergence of PLETHORA and SCARECROW transcription factor modules. Genes Dev. 2018, 32, 1085-1100. [CrossRef] [PubMed]

43. Araya, T.; Miyamoto, M.; Wibowo, J.; Suzuki, A.; Kojima, S.; Tsuchiya, Y.N.; Sawa, S.; Fukuda, H.; von Wirén, N.; Takahashi, H. CLE-CLAVATA1 peptide-receptor signaling module regulates the expansion of plant root systems in a nitrogen-dependent manner. Proc. Natl. Acad. Sci. USA 2014, 111, 2029-2034. [CrossRef] [PubMed]

44. Hofhuis, H.; Laskowski, M.; Du, Y.; Prasad, K.; Grigg, S.; Pinon, V.; Scheres, B. Phyllotaxis and rhizotaxis in Arabidopsis are modified by three PLETHORA transcription factors. Curr. Biol. 2013, 23, 956-962. [CrossRef]

45. Romani, I.; Tadini, L.; Rossi, F.; Masiero, S.; Pribil, M.; Jahns, P.; Kater, M.; Leister, D.; Pesaresi, P. Versatile roles of Arabidopsis plastid ribosomal proteins in plant growth and development. Plant J. 2012, 72, 922-934. [CrossRef]

46. Ahmed, T.; Shi, J.; Bhushan, S. Unique localization of the plastid-specific ribosomal proteins in the chloroplast ribosome small subunit provides mechanistic insights into the chloroplastic translation. Nucleic Acids Res. 2017, 45, 8581-8595. [CrossRef] 
47. Wang, W.J.; Zheng, K.L.; Gong, X.D.; Xu, J.L.; Huang, J.R.; Lin, D.Z.; Dong, Y.J. The rice TCD11 encoding plastid ribosomal protein $\mathrm{S} 6$ is essential for chloroplast development at low temperature. Plant Sci. 2017, 259, 1-11. [CrossRef]

48. Espinar-Marchena, F.J.; Babiano, R.; de la Cruz, J. Placeholder factors in ribosome biogenesis: Please, pave my way. Microb. Cell 2017, 4, 144-168. [CrossRef]

49. Zhang, J.; Yuan, H.; Yang, Y.; Fish, T.; Lyi, S.M.; Thannhauser, T.W.; Zhang, L.; Li, L. Plastid ribosomal protein $\mathrm{S} 5$ is involved in photosynthesis, plant development, and cold stress tolerance in Arabidopsis. J. Exp. Bot. 2016, 67, 2731-2744. [CrossRef]

50. Tiller, N.; Weingartner, M.; Thiele, W.; Maximova, E.; Schöttler, M.A.; Bock, R. The plastid-specific ribosomal proteins of Arabidopsis thaliana can be divided into non-essential proteins and genuine ribosomal proteins. Plant J. 2012, 69, 302-316. [CrossRef]

51. Aryamanesh, N.; Ruwe, H.; Vincis Pereira Sanglard, L.; Eshraghi, L.; Bussell, J.D.; Howell, K.A.; Small, I.; des Francs-Small, C.C. The pentatricopeptide repeat protein EMB2654 is essential for trans-splicing of a chloroplast small ribosomal subunit transcript. Plant Physiol. 2017, 173, 1164-1176. [CrossRef] [PubMed]

52. Liu, X.; Zheng, M.; Wang, R.; Wang, R.; An, L.; Rodermel, S.R.; Yu, F. Genetic interactions reveal that specific defects of chloroplast translation are associated with the suppression of var2-mediated leaf variegation. J. Integr. Plant Biol. 2013, 55, 979-993. [PubMed]

53. Kleinknecht, L.; Wang, F.; Stübe, R.; Philippar, K.; Nickelsen, J.; Bohne, A.V. RAP, the sole octotricopeptide repeat protein in Arabidopsis, is required for chloroplast 16S rRNA maturation. Plant Cell 2014, 26, 777-787. [CrossRef] [PubMed]

54. Fristedt, R.; Scharff, L.B.; Clarke, C.A.; Wang, Q.; Lin, C.; Merchant, S.S.; Bock, R. RBF1, a plant homolog of the bacterial ribosome-binding factor RbfA, acts in processing of the chloroplast 16S ribosomal RNA. Plant Physiol. 2014, 164, 201-215. [CrossRef]

55. Liu, X.; Yu, F.; Rodermel, S. An Arabidopsis pentatricopeptide repeat protein, SUPPRESSOR OF VARIEGATION7, is required for FtsH-mediated chloroplast biogenesis. Plant Physiol. 2010, 154, 1588-1601. [CrossRef]

56. Tadini, L.; Pesaresi, P.; Kleine, T.; Rossi, F.; Guljamow, A.; Sommer, F.; Mühlhaus, T.; Schroda, M.; Masiero, S.; Pribil, M.; et al. GUN1 controls accumulation of the plastid ribosomal protein S1 at the protein level and interacts with proteins involved in plastid protein homeostasis. Plant Physiol. 2016, 170, 1817-1830. [CrossRef]

57. Bobik, K.; Fernandez, J.C.; Hardin, S.R.; Ernest, B.; Ganusova, E.E.; Staton, M.E.; Burch-Smith, T.M. The essential chloroplast ribosomal protein uL15c interacts with the chloroplast RNA helicase ISE2 and affects intercellular trafficking through plasmodesmata. New Phytol. 2019, 221, 850-865. [CrossRef]

58. Ehrnthaler, M.; Scharff, L.B.; Fleischmann, T.T.; Hasse, C.; Ruf, S.; Bock, R. Synthetic lethality in the tobacco plastid ribosome and its rescue at elevated growth temperatures. Plant Cell 2014, 26, 765-776. [CrossRef]

59. Meurer, J.; Schmid, L.M.; Stoppel, R.; Leister, D.; Brachmann, A.; Manavski, N. PALE CRESS binds to plastid RNAs and facilitates the biogenesis of the $50 S$ ribosomal subunit. Plant J. 2017, 92, 400-413. [CrossRef]

60. Wu, W.; Liu, S.; Ruwe, H.; Zhang, D.; Melonek, J.; Zhu, Y.; Hu, X.; Gusewski, S.; Yin, P.; Small, I.D.; et al. SOT1, a pentatricopeptide repeat protein with a small MutS-related domain, is required for correct processing of plastid 23S-4.5S rRNA precursors in Arabidopsis thaliana. Plant J. 2016, 85, 607-621. [CrossRef]

61. Köhler, D.; Helm, S.; Agne, B.; Baginsky, S. Importance of translocon subunit Tic56 for rRNA processing and chloroplast ribosome assembly. Plant Physiol. 2016, 172, 2429-2444. [CrossRef]

62. Yagi, Y.; Ishizaki, Y.; Nakahira, Y.; Tozawa, Y.; Shiina, T. Eukaryotic-type plastid nucleoid protein pTAC3 is essential for transcription by the bacterial-type plastid RNA polymerase. Proc. Natl. Acad. Sci. USA 2012, 109, 7541-7546. [CrossRef]

63. Liu, X.; Rodermel, S.R.; Yu, F. A var2 leaf variegation suppressor locus, SUPPRESSOR OF VARIEGATION3, encodes a putative chloroplast translation elongation factor that is important for chloroplast development in the cold. BMC Plant Biol. 2010, 10, 287. [CrossRef]

64. Romani, I.; Manavski, N.; Morosetti, A.; Tadini, L.; Maier, S.; Kühn, K.; Ruwe, H.; Schmitz-Linneweber, C.; Wanner, G.; Leister, D.; et al. A Member of the Arabidopsis mitochondrial transcription termination factor family is required for maturation of chloroplast transfer RNA ${ }^{\mathrm{Ile}}$ (GAU). Plant Physiol. 2015, 169, 627-646. [CrossRef] 
65. Huang, W.; Zhu, Y.; Wu, W.; Li, X.; Zhang, D.; Yin, P.; Huang, J. The pentatricopeptide repeat protein SOT5/EMB2279 is Required for plastid rpl2 and trnK intron splicing. Plant Physiol. 2018, 177, 684-697. [CrossRef] [PubMed]

66. Jiang, T.; Zhang, J.; Rong, L.; Feng, Y.; Wang, Q.; Song, Q.; Zhang, L.; Ouyang, M. ECD1 functions as an RNA-editing trans-factor of rps14-149 in plastids and is required for early chloroplast development in seedlings. J. Exp. Bot. 2018, 69, 3037-3051. [CrossRef] [PubMed]

67. Bollenbach, T.J.; Lange, H.; Gutierrez, R.; Erhardt, M.; Stern, D.B.; Gagliardi, D. RNR1, a 3'-5' exoribonuclease belonging to the RNR superfamily, catalyzes $3^{\prime}$ maturation of chloroplast ribosomal RNAs in Arabidopsis thaliana. Nucleic. Acids. Res. 2005, 33, 2751-2763. [CrossRef] [PubMed]

68. Liu, J.; Zhou, W.; Liu, G.; Yang, C.; Sun, Y.; Wu, W.; Cao, S.; Wang, C.; Hai, G.; Wang, Z.; et al. The conserved endoribonuclease $\mathrm{YbeY}$ is required for chloroplast ribosomal RNA processing in Arabidopsis. Plant Physiol. 2015, 168, 205-221. [CrossRef]

69. Parker, M.D.; Collins, J.C.; Korona, B.; Ghalei, H.; Karbstein, K. A kinase-dependent checkpoint prevents escape of immature ribosomes into the translating pool. PLoS. Biol. 2019, 17, e3000329. [CrossRef]

70. Pratte, D.; Singh, U.; Murat, G.; Kressler, D. Mak5 and Ebp2 act together on early pre-60S particles and their reduced functionality bypasses the requirement for the essential pre-60S factor Nsa1. PLoS ONE 2013, 8, e82741. [CrossRef]

71. Konikkat, S.; Woolford, J.L. Principles of $60 \mathrm{~S}$ ribosomal subunit assembly emerging from recent studies in yeast. Biochem. J. 2017, 474, 195-214. [CrossRef] [PubMed]

72. Pestov, D.G.; Strezoska, Z.; Lau, L.F. Evidence of p53-dependent cross-talk between ribosome biogenesis and the cell cycle: Effects of nucleolar protein Bop1 on G1/S transition. Mol. Cell. Biol. 2001, 21, 4246-4255. [CrossRef] [PubMed]

73. Deisenroth, C.; Franklin, D.A.; Zhang, Y. The evolution of the ribosomal protein-MDM2-p53 pathway. Cold Spring Harb. Perspect. Med. 2016, 6, a026138. [CrossRef] [PubMed]

74. Ohbayashi, I.; Lin, C.Y.; Shinohara, N.; Matsumura, Y.; Machida, Y.; Horiguchi, G.; Tsukaya, H.; Sugiyama, M. Evidence for a role of ANAC082 as a ribosomal stress response mediator leading to growth defects and developmental alterations in Arabidopsis. Plant Cell 2017, 29, 2644-2660. [CrossRef] [PubMed]

75. Maekawa, S.; Ishida, T.; Yanagisawa, S. Reduced expression of APUM24, encoding a novel rRNA processing factor, induces sugar-dependent nucleolar stress and altered sugar responses in Arabidopsis thaliana. Plant Cell 2018, 30, 209-227. [CrossRef]

76. Kleine, T.; Leister, D. Retrograde signaling: Organelles go networking. Biochim. Biophys. Acta 2016, 1857, 1313-1325. [CrossRef]

77. Koussevitzky, S.; Nott, A.; Mockler, T.C.; Hong, F.; Sachetto-Martins, G.; Surpin, M.; Lim, J.; Mittler, R.; Chory, J. Signals from chloroplasts converge to regulate nuclear gene expression. Science 2007, 316, 715-719. [CrossRef]

78. Tameshige, T.; Fujita, H.; Watanabe, K.; Toyokura, K.; Kondo, M.; Tatematsu, K.; Matsumoto, N.; Tsugeki, R.; Kawaguchi, M.; Nishimura, M.; et al. Pattern dynamics in adaxial-abaxial specific gene expression are modulated by a plastid retrograde signal during Arabidopsis thaliana leaf development. PLoS Genet. 2013, 9, e1003655. [CrossRef]

79. Blilou, I.; Xu, J.; Wildwater, M.; Willemsen, V.; Paponov, I.; Friml, J.; Heidstra, R.; Aida, M.; Palme, K.; Scheres, B. The PIN auxin efflux facilitator network controls growth and patterning in Arabidopsis roots. Nature 2005, 433, 39-44. [CrossRef]

80. Galinha, C.; Hofhuis, H.; Luijten, M.; Willemsen, V.; Blilou, I.; Heidstra, R.; Scheres, B. PLETHORA proteins as dose-dependent master regulators of Arabidopsis root development. Nature 2007, 449, 1053-1057. [CrossRef]

81. Sabatini, S.; Beis, D.; Wolkenfelt, H.; Murfett, J.; Guilfoyle, T.; Malamy, J.; Benfey, P.; Leyser, O.; Bechtold, N.; Weisbeek, P.; et al. An auxin-dependent distal organizer of pattern and polarity in the Arabidopsis root. Cell 1999, 99, 463-472. [CrossRef]

82. Murashige, T.; Skoog, F. A revised medium for rapid growth and bioassays with tobacco tissue cultures. Physiol. Plant. 1962, 15, 473-497. [CrossRef]

83. Edwards, K.; Johnstone, C.; Thompson, C. A simple and rapid method for the preparation of plant genomic DNA for PCR analysis. Nucleic Acids Res. 1991, 19, 1349. [CrossRef] [PubMed] 
84. Horiguchi, G.; Gonzalez, N.; Beemster, G.T.S.; Inzé, D.; Tsukaya, H. Impact of segmental chromosomal duplications on leaf size in the grandifolia-D mutants of Arabidopsis thaliana. Plant J. 2009, 60, 122-133. [CrossRef] [PubMed]

85. Kojima, K.; Tamura, J.; Chiba, H.; Fukada, K.; Tsukaya, H.; Horiguchi, G. Two nucleolar proteins, GDP1 and OLI2, function as ribosome biogenesis factors and are preferentially involved in promotion of leaf cell proliferation without strongly affecting leaf adaxial-abaxial patterning in Arabidopsis thaliana. Front. Plant Sci. 2018, 8, 2240. [CrossRef] [PubMed]

86. Clough, S.J.; Bent, A.F. Floral dip: A simplified method for Agrobacterium-mediated transformation of Arabidopsis thaliana. Plant J. 1998, 16, 735-743. [CrossRef]

87. Truernit, E.; Bauby, H.; Dubreucq, B.; Grandjean, O.; Runions, J.; Barthélémy, J.; Palauqui, J.C. High-resolution whole-mount imaging of three-dimensional tissue organization and gene expression enables the study of phloem development and structure in Arabidopsis. Plant Cell 2008, 20, 1494-1503. [CrossRef]

88. Hasegawa, J.; Sakamoto, Y.; Nakagami, S.; Aida, M.; Sawa, S.; Matsunaga, S. Three-dimensional imaging of plant organs using a simple and rapid transparency technique. Plant Cell Physiol. 2016, 57, 462-472. [CrossRef]

89. Kapila, J.; De Rycke, R.; Van Montagu, M.; Angenon, G. An Agrobacterium-mediated transient gene expression system for intact leaves. Plant Sci. 1997, 122, 101-108. [CrossRef]

90. D'Aoust, M.A.; Lavoie, P.O.; Belles-Isles, J.; Bechtold, N.; Martel, M.; Vézina, L.P. Transient expression of antibodies in plants using syringe agroinfiltration. Methods Mol. Biol. 2009, 483, 41-50.

91. Tanaka, Y.; Kimura, T.; Hikino, K.; Goto, S.; Nishimura, M.; Mano, S.; Nakagawa, T. Gateway vectors for plant genetic engineering: Overview of plant vectors, application for bimolecular fluorescence complementation (BiFC) and multigene construction. In Genetic Engineering-Basics, New Applications and Responsibilities; Barrera-Saldaña, H.A., Ed.; InTech: Rijeka, Croatia, 2012.

92. Livak, K.J.; Schmittgen, T.D. Analysis of relative gene expression data using real-time quantitative PCR and the $2^{-\Delta \Delta C T}$ Method. Methods 2001, 25, 402-408. [CrossRef] [PubMed] 